\title{
Change in mental health, physical health, and social relationships during highly restrictive lockdown in the COVID-19 pandemic: Evidence from Australia
}

\author{
Shane L. Rogers ${ }^{\text {Corresp., } 1}$, Travis Cruickshank ${ }^{2}$ \\ ${ }^{1}$ School of Arts and Humanities, Edith Cowan University, Joondalup, Western Australia, Australia \\ 2 School of Medical and Health Sciences, Edith Cowan University, Joondalup, Western Australia, Australia \\ Corresponding Author: Shane L. Rogers \\ Email address: shane.rogers@ecu.edu.au
}

Background. A novel coronavirus first reported in Wuhan City in China in 2019 (COVID-19) developed into a global pandemic throughout 2020. Many countries around the world implemented strict social distancing policies to curb the spread of the virus. In this study we aimed to examine potential change in mental/physical health and social relationships during a highly restrictive COVID-19 lockdown period in Australia during April 2020.

Methods. Our survey $(n=1599)$ included questions about concerns, social behaviour, perceived change in relationship quality, social media use, frequency of exercise, physical health, and mental health during COVID-19 lockdown (April, 2020).

Results. When estimating their mental health for the previous year $13 \%$ of participants reported more negative than positive emotion, whereas this increased to $41 \%$ when participants reflected on their time during COVID-19 lockdown. A substantial proportion (39-54\%) of participants reported deterioration in mental health, physical health, financial situation, and work productivity. However, most of these participants reported 'somewhat' rather than 'a lot' of deterioration, and many others reported 'no change' (40-50\%) or even 'improvement' (6-17\%). Even less impact was apparent for social relationships ( $\sim 68 \%$ reported 'no change') as participants compensated for decreased face-to-face interaction via increased technology-mediated interaction.

Conclusions. The psychological toll of COVID-19 on Australians may not have been as large as other parts of the world with greater infection rates. Our findings highlight how technology-mediated communication can allow people to adequately maintain social relationships during an extreme lockdown event. 
1 Change in mental health, physical health, and social 2 relationships during highly restrictive lockdown in the 3 COVID-19 pandemic: Evidence from Australia

4

\author{
Shane L. Rogers ${ }^{1}$, Travis Cruickshank ${ }^{2}$ \\ ${ }^{1}$ School of Arts and Humanities, Edith Cowan University, Joondalup, Western Australia, \\ Australia \\ ${ }^{2}$ School of Medical and Health Sciences, Edith Cowan University, Joondalup, Western \\ Australia, Australia
}

Corresponding Author:

Shane Rogers ${ }^{1}$

270 Joondalup Drive, Joondalup, Western Australia, 6027, Australia

Email address: shane.rogers@ecu.edu.au

\title{
Abstract
}

Background. A novel coronavirus first reported in Wuhan City in China in 2019 (COVID-19) developed into a global pandemic throughout 2020. Many countries around the world implemented strict social distancing policies to curb the spread of the virus. In this study we aimed to examine potential change in mental/physical health and social relationships during a highly restrictive COVID-19 lockdown period in Australia during April 2020.

Methods. Our survey $(n=1599)$ included questions about concerns, social behaviour, perceived change in relationship quality, social media use, frequency of exercise, physical health, and mental health during COVID-19 lockdown (April, 2020).

Results. When estimating their mental health for the previous year $13 \%$ of participants reported more negative than positive emotion, whereas this increased to $41 \%$ when participants reflected on their time during COVID-19 lockdown. A substantial proportion (39$54 \%$ ) of participants reported deterioration in mental health, physical health, financial situation, and work productivity. However, most of these participants reported 'somewhat' rather than 'a lot' of deterioration, and many others reported 'no change' (40-50\%) or even 'improvement' (6-17\%). Even less impact was apparent for social relationships ( 68\% reported 'no change') as participants compensated for decreased face-to-face interaction via increased technology-mediated interaction.

Conclusions. The psychological toll of COVID-19 on Australians may not have been as large as other parts of the world with greater infection rates. Our findings highlight how technology-mediated communication can allow people to adequately maintain social relationships during an extreme lockdown event. 


\section{Introduction}

43

44

45

46

47

48

49

50

51

52

53

54

55

56

57

58

59

60

61

62

63

64

65

66

67

68

69

70

71

72

The year 2020 was dominated by the influence of the novel coronavirus COVID-19 pandemic (Gruber et al., 2020; Hsiang et al., 2020). The disruption caused directly by virus containment policies, and the flow on effects of economic decline, were a source of stress impacting populations around the world (Gruber et al., 2020; Holmes et al., 2020). The present study adds to the literature examining the mental health impacts of the COVID-19 pandemic by focusing on the experience of people in Australia. We report the findings of a survey undertaken in April 2020 when the Australian government had implemented very strict social distancing policies to contain the virus. We focus on quantifying the emotional well-being of participants during lockdown, and the impact on social relationships and communication patterns. While studies from around the world have consistently reported broad negative impacts of lockdowns on mental health, it is less understood how different types of social relationships might have been impacted by lockdown experiences.

\section{The impact of COVID-19 lockdown on mental health around the world, and in Australia}

Government policies enforcing restrictive lockdown to curb the spread of COVID-19 have the potential to negatively impact on fundamental psychological needs. According to self-determination theory (SDT) three core psychological needs are competence, autonomy and relatedness (Ryan \& Deci, 2000). Mandated social distancing during a pandemic may detract from an individual's sense of autonomy (i.e., sense of personal control and freedom) and relatedness (i.e., sense of closeness to other people). The flow on negative impact on the economy may further exacerbate stress as people feel a threat to their competence (i.e., sense of self-efficacy) as jobs are threatened or lost. Similarly, the same kind of logic can be applied to Maslow's hierarchy of needs that includes physiological, safety, social, esteem, and self-actualisation elements (For a discussion see: Ryan et al., 2020).

Quarantine (lockdown) during prior pandemics such as the severe acute respiratory syndrome (SARS) and Middle East respiratory syndrome (MERS) were reported to negatively affect psychological well-being (Brooks et al., 2020). Research on people's experience during COVID-19 lockdowns around the world have produced consistent findings of increased levels of stress, anxiety and depression (Baloch et al., 2021; Benke et al., 2020; Bruno et al., 2021; Ebrahimi et al., 2020; Fiorenzato et al., 2020; Gao et al., 2020; Hamadani et al., 2020; Holingue et al., 2020; Holman et al., 2020; Huang \& Zhao, 2020; Kalaitzaki, 2020; Lee, 2020; Marashi et al., 2020; Mazza et al., 2020; Ozamiz-Etxebarria et al., 2020; Patrick et al., 
2020; Pierce et al., 2020; Qiu et al., 2020; Roy et al., 2020; Sameer et al., 2020; Saraswathi et al., 2020; Twenge \& Joiner, 2020; Wang et al., 2020; Zacher \& Rudolph, 2020).

Factors reported as being associated with higher levels of emotional distress during lockdown are being younger, female, having lower education, having pre-existing medical conditions, increased social media use, rumination on COVID-19, (Baloch et al., 2021; Benke et al., 2020; Bruno et al., 2021; Bu et al., 2021; Ebrahimi et al., 2020; Fiorenzato et al., 2020; Gao et al., 2020; Holman et al., 2020; Hsiang et al., 2020; Huang \& Zhao, 2020; Kalaitzaki, 2020; Lee, 2020; Mazza et al., 2020; Ozamiz-Etxebarria et al., 2020; Qiu et al., 2020; Roy et al., 2020; Wang et al., 2020). Whereas keeping physically and socially active have been reported as protective factors (Brand et al., 2020; Bu et al., 2021; Ebrahimi et al., 2020; Galle et al., 2020; Marashi et al., 2020)

Some Australian surveys have been conducted showing that the lockdown experience, similar to other parts of the world, had a broadly negative impact on mental health (Biddle et al., 2020a; Brand et al., 2020; Fisher et al., 2020; Li et al., 2020; Newby et al., 2020; Phillipou et al., 2020; Rossell et al., 2021; Stanton et al., 2020; Titov et al., 2020; van Agteren et al., 2020; Westrupp et al., 2021). In a survey of 5070 Australians in the first week of April 2020, Newby et al. (2020) found that $55 \%$ of respondents felt their mental health had worsened a little, and $23 \%$ a lot. Primary worries underlying this were that $50 \%$ or more indicated worrying about catching the virus, feeling moderately-extremely lonely, and feeling uncertain about their financial situation. In a survey with 13,829 respondents, Fisher et al. (2020) also found overall elevated levels of psychological distress.

\section{The potential impact of COVID-19 lockdown on social relationships}

One underlying psychological mechanism to explain how COVID-19 lockdown might reduce mental health is via negative impacts on social relationships. Social relationships require maintenance where the extent of required maintenance can vary a great deal depending on the closeness of the relationship, and personal qualities and preferences (Blieszner \& Ogletree, 2017; Fehr, 2004; Mesch \& Talmund, 2006; Ogolsky \& Bowers, 2012). COVID-19 lockdown experiences have the potential to significantly impair core aspects of relationship maintenance by disrupting the frequency and quality of shared experiences, and interpersonal communication patterns. This could be associated with psychological consequences such as a decreased sense of closeness and a reduction in perceived relationship quality (Aleman \& Sommer, 2020; Lardone et al., 2020).

Engaging in shared activities/experiences has been identified as one key aspect of relationship maintenance (Daniels et al., 2017; Girme et al., 2014; Jolly et al., 2019; Mesch \& Talmund, 2006; Rossignac- 
105 Milon \& Higgins, 2018). The closure of sources of social activities (e.g., restaurants, bars, sporting clubs, 106 gyms, movie theatres, etc.) during COVID-19 lockdown arguably has the potential to impair social 107 relationships via disrupting engagement in shared activities for relationship maintenance. While engaging in shared activities can facilitate social bonds, so too can the simple act of conversing with others (Rossignac-Milon \& Higgins, 2018). Communicative acts such as self-disclosure (Sprecher \& Treger, 2015), reminiscing (Roberts, 2018), sharing news (Reis et al., 2010) and gossip (Yucel et al., 2020), all have the potential to serve as bonding experiences. Therefore social distancing policies associated with COVID-19 lockdown has potential to reduce the amount or frequency of social interaction, as people spend more time at home.

Lockdown also has the potential to impact upon the type of social interaction, with an increased amount of communication via technology (e.g., phone, email, social media) to compensate for reduced opportunities for face-to-face interaction. Research suggests that communication via technology can be considered as impoverished compared to face-to-face communication via a reduction in certain verbal

118 (e.g., tone of voice) or non-verbal (e.g., eye contact, gestures, or body posture) communicative cues 119 (Colvin et al., 2004; Kock, 2002, 2004; Lieberman \& Schroeder, 2020; Walther, 1996; Walther \& Parks, 2002). As a consequence it is not surprising that people generally have a preference for face-to-face communication over technology-mediated communication in most instances (Flaherty et al., 1998; Wilson et al., 2020). Therefore, even if a person tries to compensate for reduced face-to-face interaction via a corresponding increase in technology-mediated communication, theoretically there remains potential for a negative impact on perceived relationship quality if the subsequent technology-mediated communication is experienced as a lesser form of interaction.

\section{Research investigating social relationships during COVID-19 lockdown}

As discussed in the prior section, it is reasonable to expect that social relationships might be negatively impacted during COVID-19 lockdown. However, recent studies that have investigated loneliness during the pandemic have been reporting mixed findings. Some studies have reported an increase in loneliness (Bu et al., 2020; Killgore et al., 2020; van Tilburg et al., 2020), whereas others have reported there has been no significant increase in loneliness during lockdowns compared to pre-pandemic levels (Groarke et al., 2020; Luchetti et al., 2020).

Few studies have directly asked targeted questions about perceived relationship quality during the pandemic (Biddle et al., 2020b; Bulow et al., 2020; Cooper et al., 2020; Philpot et al., 2021), and even less about the use of technology-mediated communication (Monin et al., 2020). In a recent Australian 
137 study Biddle et al. (2020b) asked their 3,249 respondents from the general public 'How has the quality of

138 your relationships with other people/family members in your household changed since the spread of 139 COVID-19?'. Responses were: $2 \%$ a lot more difficult/strained, $15 \%$ a little more difficult/strained, 55\% no 140 change, $23 \%$ a little closer/stronger, and 5\% a lot closer/stronger. Biddle et al.'s (2020b) study provides 141 some evidence to suggest that during the lockdown in April there may not have been any broad large 142 negative impact on social relationships in the Australian population.

143

\section{The present study}

145 Our study aims to contribute to the emerging literature on the mental and physical health impacts 146 of government mandated lockdown policies on the public during COVID-19. We also take an in-depth look 147 at how communication patterns changed regarding face-to-face and technology-mediated 148 communication to examine how these different modes of communication are associated with self149 reported quality of social relationships. Our survey was conducted from 14th-30th April in 2020 when all 150 non-essential businesses were closed, and people were not supposed to congregate in groups larger than 151 two people outside of their immediate household members. We were anticipating that like other 152 Australian studies investigating the same period in time, we would find a substantial portion of 153 participants self-reporting deterioration across their mental health, physical health, and financial situation 154 (Fisher et al., 2020; Newby et al., 2020; Phillipou et al., 2020).

Based on background psychological literature on relationship maintenance, and the impoverished nature of technology mediated communication (when compared to face-to-face communication), we were initially predicting that COVID-19 lockdown would be associated with a negative impact on social relationships in our sample. However, based on Biddle et al.'s (2020b) results (that was published after our study commenced), we were subsequently anticipating that social relationships might not be greatly impacted for most individuals. Extending upon Biddle et al. (2020b), we further explore potential changes in participant behaviour regarding the extent of face-to-face and technology-mediated social interaction, and whether (or not) changes in social interaction are associated with changes in perceived relationship quality.

We also asked participants about a range of concerns they were experiencing about COVID-19 to compare how concerns about their personal relationships compares with other concerns. If we find that social relationships are not being heavily impacted, then we also expect that self-reported concerns about social relationships will overall be lower compared to other concerns. Prior research has indicated that 
169 (Ebrahimi et al., 2020; Newby et al., 2020; Saraswathi et al., 2020; Timming et al., 2021; Wang et al., 2020).

170 We also look at other factors that have been examined in other parts of the world but not yet given much 171 attention by Australian researchers (i.e., frequency of exercise, COVID-19 rumination, and social media 172 exposure). Based on what has recently been reported in the literature, we hypothesize that in our sample 173 higher frequency of exercise will be positively associated with emotional well-being (Bu et al., 2021; 174 Ebrahimi et al., 2020; Galle et al., 2020), whereas increased rumination on COVID-19 and increased use of 175 social media will be negatively associated with emotional well-being (Bu et al., 2021; Gao et al., 2020; 176 Hsiang et al., 2020; Lee, 2020; Roy et al., 2020).

177

178 Materials \& Methods

179

180

181

\section{Participants and Procedure}

An online survey was disseminated between 14th-30th April 2020 via social media channels 182 (primarily Facebook). We received 1599 responses, 78\% female. Age of participants in years: 18-21 (6\%), 22-25 (4\%), 26-30 (11\%), 31-35 (13\%), 36-40 (11\%), 41-50 (22\%), 51-60 (18\%), 61-70 (11\%), 71+ (3\%). Employment status: Full-time (44\%), part-time (19\%), casual (12\%), stay at home parent (8\%), retired (9\%), unemployed (8\%). The industry worked in: Health care and social assistance (24\%), Education and training (22\%), Professional, scientific and technical services (9\%), retail trade (6\%), administration (5\%), with the remaining $44 \%$ spread across other industries in smaller proportions. Most of our participants resided in Western Australia (81\%), with the remainder of the sample coming from the various other Australian states and territories. Most participants (75\%) were in a committed relationship at the time of the study. The lockdown period began from the start of April 2020, where gatherings were restricted to two people (except for immediate members of households). Participants in our sample had been in lockdown for an average of 18.84 days $(S D=4.62, \min =14, \max =30)$. Prior to running the survey, ethics approval was obtained from Edith Cowan University (Ref: 2020-01305-ROGERS). Informed consent was obtained from a dedicated question embedded at the beginning of the survey asking participants to consent for their data to be used for research purposes.

\section{Survey Measures}

\section{Emotional and physical well-being}

We measured emotional and physical well-being via the Brief Emotional Experience Scale (BEES) 
202 Rogers, 2016; Skead et al., 2018). For the BEES, participants rate how they are emotionally feeling for the 203 adjectives Happy, Worried, Calm, Sad, Confident, and Afraid, on a response scale: (1) Not at all (2) A little 204 bit (3) A lot. For the BEEPS, participants to rate how they are physically feeling for the adjectives Healthy, 205 Lethargic, Strong, Unfit, Energetic, Weak, using same response scale as the BEES. For both measures an 206 overall score can be created by averaging across the three positive and negative adjectives separately, 207 and then subtracting the negative from the positive score. This provides an overall score that can range 208 from +3 to -3 where a score above zero indicates greater positive than negative emotion, and a score 209 below zero greater negative than positive emotion. The BEES and BEEPS were repeated twice in the 210 survey. Participants answered by reflecting on their past month, and then answered a second time 211 reflecting on the same time last year. In the present study Cronbach Alpha values for the BEES and BEEPS 212 across the four measurements ranged from .85 to .87

213

214

Exercise

215 We measured frequency of exercise via questions previously used by Skead et al. (Skead \& Rogers, 216 2016; Skead et al., 2018). Participants rated how often they had been engaging in light (e.g., walking), 217 moderate (e.g., jogging), and high (e.g., running) intensity exercise, on a response scale: (0) Never (1) 218 About once a week or less (2) A few times per week (3) About once a day. These questions were asked 219 twice, by asking participants to reflect on the past month, and then also on the same time last year. As 220 per Skead and Rogers (2016) we created a composite exercise variable giving greater weightings to 221 moderate and high intensity exercise via the formula: Low $+(2 *$ moderate $)+(3 *$ high $)$. This provides a 222 frequency of exercise score that ranges from a minimum of zero to maximum of 18.

223

224

\section{Perceived impact of COVID-19 lockdown on different aspects of life, and concerns about COVID-19}

Participants were asked how COVID-19 lockdown may have impacted upon their mental health, physical health, financial situation, and social relationships over the past month on a response scale: (1) Deteriorated a lot (2) Deteriorated somewhat (3) no change (4) Improved somewhat (5) Improved a lot. Participants were also asked how concerned they were about several COVID-19 related aspects, such as the ability to purchase necessities and impact on the economy, on a response scale: (1) Not concerned (2) Slightly concerned (3) Very concerned (4) Extremely concerned. The full list of concerns is shown in results sub-section 'Concerns related to COVID-19'.

232

\section{Attention given to COVID-19}


We assessed participant attention given to COVID-19 over the past month via four items that

235

236

237

238

239

\section{0}

241

242

243

244

245

246

247

248

249

250

251

252

253

254

255

256

257

258

259

260

261

262

263

264

265

asked how much they had been thinking about COVID-19, talking with others about COVID-19, following information via news stories, and via more official sources. These questions were rated on a response scale: (1) About once a week or less (2) A few times per week (3) About once a day (4) Multiple times per day.

\section{Self-perceived social behaviour change due to COVID-19}

We asked participants to reflect on a series of questions regarding their social behaviour change due to COVID-19. The first three items asked about how much they had been distancing from others, isolating from others, and spending time on social media. The remainder of items asked the extent to which they had been interacting with their partner, friends, family, or work colleagues either face-to-face, or via technologically mediated modes of communication (i.e., phone, email, online). All these items used a scale with the following response items: (1) A lot less (2) Somewhat less (3) No change (4) Somewhat more (5) A lot more.

\section{Results}

Throughout our results we use Pearson $r$ as a measure of effect size for mean comparison tests, in addition to also reporting it for standard correlation analyses (Field, 2018). Our interpretation of the magnitude of $r$ values follows broad guidelines of small (0.1), medium (0.3), and large (0.5) provided by Cohen (1992).

Perceived impact of COVID-19 lockdown on emotional well-being, physical well-being, relationships, and work

We asked participants a series of questions about their emotional well-being, physical well-being, and exercise reflecting over the prior month, and for the same time last year. The results from these measures are presented in Figure 1. Both emotional $(t(1598)=24.45, p<.001, r=.52)$ and physical $(t(1598)=19.58, p<.001, r=.44)$ well-being were found to be lower during the COVID-19 lockdown period compared to participant estimates of their health the same time last year. More specifically, while $13 \%$ of participants estimated greater negative than positive emotion for the prior year (i.e., BEES score $<0$ ), this increased to $41 \%$ of participants for the prior month. Similarly, $19 \%$ of participants reported greater negative than positive physical well-being for the prior year (i.e., BEEPS score $<0$ ), increasing to $42 \%$ for

Peer) reviewing PDF | (2021:02:57922:2:0:NEW 21 Jun 2021) 
266

267

268

269

270

271

272

273

274

275

276

277

278

279

280

281

282

283

284

285

286

287

288

289

290

291

292

293

294

295

296

297

the prior month. As indicated by the effect sizes $(r)$, and as can be seen in Figure 1, these represent statistically moderate effects. When comparing estimates of last year with the present month, we also found an overall decrease in self-reported frequency of exercise $(t(1598)=9.80, p<.001, r=.24)$. However as indicated by the effect size $(r)$, and can be seen in Figure 1 , this represents a relatively small effect.

<insert Figure 1. here>

Correlations among self-reported emotional well-being, physical well-being, and exercise, during lockdown and last year, are presented in Table 1. Emotional well-being (BEES) was found to be positively associated with physical well-being (BEEPS) during lockdown (Pearson $r=.60, p<.001$ ), and last year (Pearson $r=.57, p<.001$ ). Only weak positive associations between current month and last year values were found for both the emotional wellbeing and physical wellbeing suggesting that participants were able to dissociate last year from the current year when making their appraisals. Frequency of exercise was found to positively associate with physical well-being, during lockdown (Pearson $r=.40, p<.001$ ), and last year (Pearson $r=.48, p<.001$ ). Whereas there were only weak positive associations between frequency of exercise and emotional well-being. This replicates prior work by Skead and Rogers (2016) that suggests exercise may have an indirect benefit for mental well-being via enhancing one's sense of physical wellbeing.

\section{<insert Table 1 here>}

Perceived impact of COVID-19 lockdown on emotional well-being, physical well-being, relationships, and work

We directly asked participants to estimate the impact of COVID-19 lockdown regarding their mental health, physical health, finances, work, and relationships, see Figure 2. A substantial proportion of participants indicated at least some deterioration of their mental health (54\%), physical health (41\%), financial situation (39\%), and productivity with work (41\%). Note that for most individuals reporting a deterioration, the response is somewhat rather than a lot (see Figure 2.). Also, except for mental health, the most common response for physical health, financial situation, and work productivity was no change. Interestingly, there appears less impact on social relationships, as only approximately $17 \%$ indicated deterioration across different types of relationships, while approximately $66-72 \%$ reported no change, and $8-16 \%$ reported improvement. As will be shown later in the results section, many participants 
298

299

300

301

302

303

304

305

306

307

308

309

310

311

312

313

314

315

316

317

318

319

320

321

322

323

324

325

326

327

328

329

330

331

332

appeared to compensate for a decrease in face-to-face contact using technology to keep in contact with others.

<insert Figure 2. here>

Inter-correlations among the variables in Figure 2 are presented in Table 2. Participants' present month emotional well-being score was positively associated with participants' self-rating of COVID-19 lockdown impact on their mental health (Spearman $r=.64, p<.001$ ), and present month physical wellbeing was positively associated with their rating of COVID-19 lockdown impact on their physical health (Spearman $r=.49, p<.001$ ). There are only weak positive associations among most other variables.

<insert Table 2. here>

\section{Concerns related to COVID-19}

We asked participants the extent they were concerned about a range of social and economic issues due to COVID-19, see Figure 3. We found a substantial proportion of participants to have concern across all issues, however the two stand outs are concern about friends and family catching COVID-19 (63\% very/extremely concerned), and a negative impact on the economy (73\% very/extremely concerned). Note that concern over personal relationships suffering is much lower in comparison ( $20 \%$ very/extremely concerned).

\section{<insert Figure 3. here>}

Inter-correlations among the different concerns, and relationships with emotional well-being measures, are presented in Table 3. All concerns were found to be negatively associated with emotional well-being. Associations among concerns varied depending on the similarity of the concerns. As an example, a strong association was found between self-concern catching COVID-19 and concern for friends/family catching COVID-19 (Spearman $r=.60, p<.001$ ). Whereas these concerns about catching the virus were only weakly positively associated with all other concerns.

<insert Table 3 here>

Amount of personal attention given to COVID-19

Peer] reviewing PDF | (2021:02:57922:2:0:NEW 21 Jun 2021) 
We expected that participants would report giving a lot of personal attention to COVID-19

334

335

336

337

338

339

340

341

342

343

344

345

346

347

348

349

350

351

352

353

354

355

356

357

358

359

360

361

362

363

364

365

<insert Figure 4. here>

Inter-correlations among items are presented in Table 4. Across the items the clearest negative association with emotional well-being was the item 'thinking about COVID-19' (Spearman $r=-.27, p<$ .001). Therefore, we found a moderate association between rumination about COVID-19 and lower emotional well-being.

<insert Table 4. here>

\section{Perceived changes in social behaviour due to COVID-19}

Many participants reported a substantial shift in their social behaviour in response to the social distancing policies in place at the time of the survey, see Figure 5. Many participants reported more distancing from others (88\%), isolating themselves from other people (75\%), and spending more time on social media (63\%). Spending more time on social media was found to be negatively associated with BEES emotional well-being (Spearman $r=-.28, p<.001$ ), and perceived change in mental health (Spearman $r=$ $-.25, p<.001)$. Participant's face-to-face interaction time typically increased for time with one's partner (52\%), and decreased for time with family (54\%), friends (86\%), and work colleagues (64\%). Whereas technology mediated interaction time typically increased for family (57\%), friends (56\%), and work colleagues (49\%). Therefore, results suggest that people were compensating for the decreased face-toface interaction time with increased technology mediated interaction time.

<insert Figure 5. here>

\section{Associations between change in communication and change in relationship quality}

Correlations between perceived change in relationship quality and change in the extent of both face-to-face and technology-mediated communication are presented in Table 5. A consistent weakmoderate positive association between change in face-to-face interaction and change in each type of relationship was found. Weak-moderate positive relationships were also found between change in

Peer] reviewing PDF | (2021:02:57922:2:0:NEW 21 Jun 2021) 
366

367

368

369

370

371

372

373

374

375

376

377

378

379

380

381

382

383

384

385

386

387

388

389

390

391

392

393

394

395

396

397

398

technology mediated communication and perceived change in quality for relationships with family, friends, and work colleagues (but not partner).

<insert Table 5. here>

There is a high proportion of participants reporting no change in perceived relationship quality across all relationship types. Therefore, the relatively low correlations in Table 5 might represent an under-representation of the strength of association between the variables due to a lack of spread across the response options, and/or non-linear patterns of association. In Figure 6 we graphically present the associations between the variables which helps to provide a clearer indication of how both face-to-face and technology-mediated communication are associated with perceived change in relationship quality. For example, Figure 6(A) shows that most of the participants in a relationship that felt their relationship with their partner had improved stated their face-to-face communication had increased (78\%). Whereas this percentage is substantially lower in participants reporting no change (49\%) or a deterioration in relationship quality with their partner (39\%). A similar pattern is also evident across the other types of relationships such as (B) family, (C) friends, and (D) co-workers, see Figure 6. This indicates that the positive association between more face-to-face communication and improved relationship quality might be stronger than the correlation values suggest.

A similar pattern is also evident for technology-mediated communication across relationship types (except for relationship with partner). For example, the proportion of the sample that reported an improvement in friendships quality typically also reported an increased level of technology-mediated communication (85\%). Whereas the amount of participants reporting an increased level of technologymediated communication was comparatively lower for participants reporting no change (59\%) or a deterioration of friendship quality $(40 \%)$, see Figure $6(\mathrm{G})$. This indicates that the positive association between more technology-mediated communication and improved relationship quality might be stronger than the correlation values suggest. Overall, our findings indicate that both face-to-face interaction and technology-mediated interaction had a role to play in maintaining relationships during the April lockdown period.

<insert Figure 6. here>

Peer) reviewing PDF | (2021:02:57922:2:0:NEW 21 Jun 2021) 
The main aims of this study are to contribute to the growing body of literature that indicates

400

401

402

403

404

405

406

407

408

409

410

411

412

413

414

415

416

417

418

419

420

421

422

423

424

425

426

427

428

429

430

government mandated lockdown policies can have potential negative consequences for public mental and physical health. We also sought to examine how changes in face-to-face and technology-mediated communication might be associated with changes in perceived relationship quality during a lockdown event. We surveyed 1599 Australian adults during a period of severe lockdown restrictions in Australia (April, 2020). Our study was conducted during a period in Australia where such a lockdown was unprecedented, and COVID-19 cases had risen dramatically just prior (i.e., in March) to the survey period. At the population level, the 5900 cases in March represented approximately $0.02 \%$ of the Australian population. At the time of the survey, the lockdown appeared to be working in curbing the spread of infections, however a great deal of uncertainty remained at the time.

From a psychological perspective, our study examines a context where the public were largely not experiencing direct adverse experiences from the virus (i.e., self or loved ones having the virus). Only $0.2 \%$ of our sample reported personally contracting COVID-19, $6 \%$ stated they had friends or family that had contracted COVID-19, and 10\% stated they had members of their extended network with COVID-19. Therefore, we argue that in our sample participants are generally experiencing indirect adverse experiences via stress about the potential spread of the virus (i.e., $63 \%$ of participants reported being very/extremely concerned about their loved ones catching the virus), and adverse effects of lockdown on the economy (i.e., $73 \%$ very/extremely concerned about the economy).

\section{Emotional and physical well-being, exercise, concerns, social media use, and COVID-19 rumination}

We found that during COVID-19 lockdown $41 \%$ and $42 \%$ of participants were experiencing greater negative than positive emotional and physical well-being, respectively. This contrasts with only $13 \%$ and $19 \%$ reporting greater negative than positive emotional and physical well-being when estimating how they were feeling the same time last year. Therefore, our results are consistent with other recent findings from around the world that the COVID-19 lockdown experience is associated with a negative impact on well-being for a substantial proportion of the public (Biddle et al., 2020a; Ebrahimi et al., 2020; Fisher et al., 2020; Gao et al., 2020; Huang \& Zhao, 2020; Lee, 2020; Mazza et al., 2020; Newby et al., 2020; OzamizEtxebarria et al., 2020; Phillipou et al., 2020; Pierce et al., 2020; Qiu et al., 2020; Roy et al., 2020; Twenge \& Joiner, 2020; Wang et al., 2020; Westrupp et al., 2021).

We only observed a small decrease in frequency of exercise. One potential reason for only a minor reduction in exercise is that our sample appears to have been relatively sedentary prior to the lockdown, see Figure $1(C)$. Another reason is that some individuals may have increased exercise (with more time on 
431 their hands) that cancels out those exercising less. Consistent with other recent studies (Brand et al., 2020;

432 Bu et al., 2021; Ebrahimi et al., 2020; Galle et al., 2020; Marashi et al., 2020), we found a link between 433 frequency of exercise with both physical and mental well-being suggesting that keeping physically active 434 can potentially act as a buffer for stress during lock-down. Codella et al. (2020) have also pointed out that 435 being physically active has benefits for maintaining a healthy immune system, which is obviously very 436 relevant during a pandemic.

437 We acknowledge that relying on participant retrospective accounts of their mental health, 438 physical health and exercise from the previous year is not ideal. This approach has the potential to 439 exaggerate differences between pre- and post-lockdown ratings. This is because the reflection on last year 440 might be biased by current feelings. However, the correlations between lockdown and last year estimates 441 for mental health $(r=.18)$ and physical health $(r=.34)$ were not strong, which does provide some evidence 442 to suggest that participants were able to dissociate current feelings from prior feelings. Comparatively, 443 current estimate of frequency of exercise was more strongly related to prior year estimates of exercise $(r$ $444=.56)$.

When asking participants to directly rate the impact they perceived COVID-19 lockdown was 446 having on their mental health, our results are similar with another Australian survey by Newby et al. 447 (2020). In our sample 44\% felt their mental health had deteriorated somewhat, and 10\% a lot. In Newby 448 et al.'s (2020) study 55\% felt their mental health had worsened a little, and $23 \%$ a lot. The higher level of 449 distress in Newby et al.'s study (2020) might be attributed to their data collection occurring slightly earlier 450 than ours. When their study occurred, there was less clarity that the lock-down was flattening the 451 infection rate curve. Also, they reported quite a high proportion of their participants (70\%) with prior lived experience with a mental health diagnosis. We concede a limitation of our own study was that we did not query this with our own participants, however we expect that if we had such a question in our study the figure would be lower than $70 \%$. Additionally, our sample is primarily from Western Australia whereas their sample contained more people from the Eastern states. As can be seen in Figure 7 the number of recorded COVID-19 cases in the month of March leading up to the lockdown was higher in the Eastern states of New South Wales (NSW), Victoria (VIC) and Queensland (QLD) compared to Western Australia 458 (WA). When considering population size, the differences were negligible, as WA has a substantially lower population size compared to these other Australian states. However, at the time the media consistently reported in terms of number of cases and communicated that the situation was worse in the Eastern 
462

463

464

465

466

467

468

469

470

471

472

473

474

475

476

477

478

479

480

481

482

483

484

485

486

487

488

489

490

491

492

493

states compared to Western Australia and a potential reason for the difference between our findings with those of Newby et al. (2020).

<insert Figure 7. here>

We are hesitant to frame our findings as demonstrating any substantial increase in clinical levels of distress. We argue that diminished well-being during such an experience (i.e., lockdown) that impacts on core psychological needs such as competence, autonomy and relatedness is a natural and understandable human reaction. We expect that most people will possess the resilience to recover quickly. However, as suggested by Gruber et al. (2020) there might be a proportion of participants for whom the lockdown experience acts as a traumatic precipitating event for the development of clinical depression or anxiety. Future research is required to better understand the precise extent of such occurrences.

Another finding of ours consistent with Newby et al. (2020) was that the dominant concerns of our participants were related to friends or family catching COVID-19 (63\% very/extremely concerned), and the economy (73\% very/extremely concerned). Consistent with research from other parts of the world (Gao et al., 2020; Hsiang et al., 2020; Lee, 2020; Roy et al., 2020), we found that such concern was perhaps influencing people to seek out COVID-19 information, as a large proportion of participants (i.e., 35\%-55\%) were monitoring sources of information about COVID-19 multiple times per day. Or alternatively, high exposure to sensationalist media coverage might have been exacerbating people's concerns (Bendau et al., 2020; Bu et al., 2021). Also, we found evidence for a high degree of rumination on COVID-19, as most participants (66\%) reported thinking about COVID-19 multiple times per day. In our study we found such rumination was associated with lower levels of emotional well-being. Additionally, we found that many people (63\%) reported engaging with social media more often, and consistent with Gao et al. (2020) we found a weak negative association with social media use and emotional well-being.

\section{Perceived change in social relationships and communication patterns during lockdown}

In our study most participants reported no deterioration in their social relationships, and most were not concerned about it. More specifically, only 13-26\% reported a deterioration in their relationships with their partner, family, friends, or work colleagues, while $66-72 \%$ reported no change, and $8-16 \%$ reported improvement. Across the relationships of family, friends, and work colleagues, face-to-face interaction time typically decreased (54-86\% of participants), while technology-mediated interaction via phone, email, or online correspondingly increased (49-57\% of participants). An exception to these findings was type of communication with one's partner, with most participants responding that they had been

Peer] reviewing PDF | (2021:02:57922:2:0:NEW 21 Jun 2021) 
494

495

496

497

498

499

500

501

502

503

504

505

506

507

508

509

510

511

512

513

514

515

516

517

518

519

520

521

522

523

524

525

spending more time interacting face-to-face with their partner (52\%), with technology-mediated communication typically unchanged (64\%).

Considering prior literature on relationship maintenance (Blieszner \& Ogletree, 2017; Fehr, 2004; Mesch \& Talmund, 2006; Ogolsky \& Bowers, 2012; Rossignac-Milon \& Higgins, 2018), media naturalness theory (Kock, 2002, 2004), and a general preference for face-to-face interaction (Flaherty et al., 1998; Wilson et al., 2020), at the outset of our study we were anticipating that a sudden decrease in face-toface interaction would be associated with diminished perceived relationship quality. On the one hand, we did find that change in face-to-face interaction was positively associated with change in relationship quality. That is, participants reporting increased face-to-face interaction also tended to be more likely to report an improvement in relationship quality. This pattern was consistent across all relationship types. However, we did also find that most people reported no change in relationship quality, which indicated no systematic large scale negative impact on relationship quality during lockdown across multiple types of social relationships (i.e., partner, family, friends, and work colleagues). This finding is consistent with recent Australian research by Biddle et al. (2020b) whom reported that a majority of participants reported no change in relationship quality with other people/family members in their household.

We offer a couple of complimentary potential explanations for this finding. First, while lockdown drastically reduces opportunity for many types of relationship maintenance experiences (e.g., going to see a movie at a cinema), it arguably also provides an over-arching experience that has potential to be a source of relationship bonding. In our study, $94 \%$ of participants reported 'talking with people about COVID-19' at least a few times per week, and $45 \%$ reported multiple times per day. Additionally, the pandemic appears to be a largely negative experience for many people around the world (Benke et al., 2020; Ebrahimi et al., 2020; Fiorenzato et al., 2020; Gao et al., 2020; Hamadani et al., 2020; Holman et al., 2020; Huang \& Zhao, 2020; Kalaitzaki, 2020; Lee, 2020; Marashi et al., 2020; Mazza et al., 2020; OzamizEtxebarria et al., 2020; Pierce et al., 2020; Qiu et al., 2020; Roy et al., 2020; Twenge \& Joiner, 2020; Wang et al., 2020; Zacher \& Rudolph, 2020), and we have reported a substantial proportion in our sample of Australians being negatively affected during lockdown. Numerous studies have indicated that shared experiences of pain, adversity, and/or hardship have the potential to act as social bonding experiences (some examples: Bastian, Jetten, \& Ferris, 2014; Bastian, Jetten, Hornsey, et al., 2014; Bastian et al., 2018; Breslin, 2019; Shaw et al., 2020).

The second potential reason why we did not find any substantial negative impact on social relationships is that we found many participants were making good use of communications technology to stay connected during the lockdown period. Across relationship types of family, friends, and work 
526

527

528

529

530

531

532

533

534

535

536

537

538

539

540

541

542

543 544 sample.

545

546

547

548

549

550

551

552

553

554

555

556

557

colleagues there was a positive association with change in technology-mediated communication and change in relationship quality. That is, participants reporting an increase in their technology-mediated communication were more likely to also report an improvement in relationship quality. Therefore, while modern communication technology such as social media has potential to reduce well-being via increasing rumination (Ohannessian et al., 2020; Parris et al., 2020) and excessive social comparison (Feinstein et al., 2013), such technologies are also arguably particularly useful for helping people keep informed and connected with others during lockdown experiences.

\section{Study limitations}

Our sample primarily consists of females (78\%), in a relationship (75\%), living in Western Australia (81\%). Therefore, our sample is not representative of the entire Australian population so generalisations from our findings should be made with caution. Our survey was advertised primarily on Facebook about people's experience during COVID-19 which may have attracted respondents who were concerned and stressed about COVID-19 to participate. Therefore, our results indicating an overall decrease in emotional/physical well-being, and high concerns about loved ones contracting the virus and concern for the economy, may be over-represented in our specific sample. Also, our sample is limited to people who are actively engaged with social media. Therefore, our findings regarding the extent of social media use, and technology-mediated communication use more broadly, may also be over-represented in our specific

In our study participants had been under COVID-19 lockdown for 2-4 weeks. It could be that a more protracted lockdown would produce quite a different result. While technology-mediated communication appeared to compensate for reduced face-to-face time in the present study, in a lengthier lockdown situation there remains the distinct possibility that reduced face-to-face contact could result in degraded social relationships. There is a need for the further development of communication technologies to be better prepared for such future possibilities. An area of current development is communication in virtual reality via head mounted display (HMD) (Pan \& Hamilton, 2018; Rosedale, 2016; Seymour et al., 2018; Seymour et al., 2019). HMD-based virtual reality has the potential to become a technologymediated mode of communication that can psychologically feel near identical to face-to-face interaction (Pan \& Hamilton, 2018; Rosedale, 2016; Seymour et al., 2018). Future research is needed to fast-track the development of this new mode of social interaction.

With a cross-sectional design, we are unable to make any confident conclusions regarding the direction of causality for the associations between variables in our study. For example, we have suggested

Peer] reviewing PDF | (2021:02:57922:2:0:NEW 21 Jun 2021) 
558 that exercise might be a protective factor against stress, however it may also be that stress reduces

559 motivation for exercise (Stults-Kolehmainen \& Sinha, 2014). We have suggested that engaging in greater

560 social media use might be exacerbating stress, but it could also be that stress is what is driving people to

561 seek out more social connection on social media (Luo \& Hancock, 2020). We have suggested that engaging

562 in greater social interaction face-to-face and via technology-mediated modes of communication can help

563 to decrease stress, but again it could be that it is stress that is motivating people to increase their

564 interaction with others as they seek social support (Sameer et al., 2020).

565

566 Conclusions

567

568

Our study within an Australian sample is consistent with emerging literature around the world

569 that lockdown experiences during COVID-19 are associated with decreased emotional and physical well-

570 being for a substantial proportion of individuals. The highest concerns reported by our participants were

571 about themselves and loved ones catching the virus, and concern for the economic impact. Many participants were found to be engaging heavily with the media to stay informed, leaving them prone to rumination about COVID-19 that for some appeared to be exacerbating their stress. We found evidence to suggest that despite such stressors, people were using technology to stay connected with others so that overall, there was not any major impact on social relationships for most individuals in our study. An increase in social media use was however also found to be a factor that might exacerbate stress, while

577 staying physically active a potential buffer against stress.

578

579

580

581

582

583

584

585

586

587

588

589

590

591

592 
593

594

595

596

597

598

599

600

601

602

603

604

605

606

607

608

609

610

611

612

613

614

615

616

617

618

619

620

621

622

623

624

625

626

627

628

629

630

631

632

633

634

635

636

637

638

639

640

641

642

\section{References}

Aleman, A., \& Sommer, I. (2020). The silent danger of social distancing. Psychological Medicine. https://doi.org/10.1017/S0033291720002597

Baloch, G. M., Sundarasen, S., Chinna, K., Nurunnabi, M., Khoshaim, H. B., Hossain, S. F. A., \& AlSukayt, A. (2021). COVID-19: exploring impacts of the pandemic and lockdown on mental health of Pakistani students. PeerJ, 9, e10612. https://doi.org/10.7717/peerj.10612

Bastian, B., Jetten, J., \& Ferris, L. J. (2014). Pain as social glue: Shared pain increases cooperation. Psychological Science, 25(11), 2079-2085.

https://doi.org/10.1177/0956797614545886

Bastian, B., Jetten, J., Hornsey, M. J., \& Leknes, S. (2014). The positive consequences of pain: A biopsychosocial approach. Personality and Social Psychology Review, 18(3), 256-279. https://doi.org/10.1177/1088868314527831

Bastian, B., Jetten, J., Thai, H. A., \& Steffens, N. K. (2018). Shared adversity increases team creativity through fostering supportive interaction. Frontiers in Psychology, 9, 2309. https://doi.org/10.3389/fpsyg.2018.02309

Bendau, A., Petzold, M. B., Pyrkosch, L., Maricic, L. M., Betzler, F., Rogoll, J., Grobe, J., Strohle, A., \& Plag, J. (2020). Associations between COVID-19 related media consumption and symptoms of anxiety, depression and COVID-19 related fear in the general population in Germany. European Archives of Psychiatry and Clinical Neuroscience, 1-9. https://doi.org/10.1007/s00406-020-01171-6

Benke, C., Autenrieth, L. K., Asselmann, E., \& Pane-Farre, C. A. (2020). Stay-at-home orders due to the COVID-19 pandemic are associated with elevated depression and anxiety in younger, but not older adults: results from a nationwide community sample of adults from Germany. Psychological Medicine, 1-2. https://doi.org/10.1017/S0033291720003438

Biddle, N., Edwards, B., Gray, M., \& Sollis, K. (2020a). Initial impacts of COVID-19 on mental health in Australia.

https://csrm.cass.anu.edu.au/sites/default/files/docs/2020/6/Mental health before and during_the_COVID_crisis.pdf

Biddle, N., Edwards, B., Gray, M., \& Sollis, K. (2020b). Mental health and relationships during the COVID-19 pandemic. https://csrm.cass.anu.edu.au/research/publications/mentalhealth-and-relationships-during-covid-19-pandemic

Blieszner, R., \& Ogletree, A. M. (2017). We get by with a little help from our friends. Generations, 41(2), 55-62. https://www.ingentaconnect.com/content/asag/gen/2017/00000041/00000002/art00009

Brand, R., Timme, S., \& Nosrat, S. (2020). When pandemic hits: Exercise frequency and subjective well-being during COVID-19 pandemic. Frontiers in Psychology. https://doi.org/10.3389/fpsyg.2020.570567 
643

644

645

646

647

648

649

650

651

652

653

654

655

656

657

658

659

660

661

662

663

664

665

666

667

668

669

670

671

672

673

674

675

676

677

678

679

680

681

682

683

684

685

686

687

688

689

690

691

692

Breslin, D. (2019). Finding collective strength in collective despair; exploring the link between generic critical feedback and student performance. Studies in Higher Education. https://doi.org/10.1080/03075079.2019.1688283

Brooks, S. K., Webster, R. K., Smith, L. E., Woodland, L., Wessely, S., Greenberg, N., \& Rubin, G. J. (2020). The psychological impact of quarantine and how to reduce it: rapid review of the evidence. The Lancet. https://doi.org/10.1016/S0140-6736(20)30460-8

Bruno, G., Panzeri, A., Granziol, U., Alivernini, F., Galli, F., Lucidi, F., Spoto, A., Vidotto, G., \& Bertamini, M. (2021). The Italian COVID-19 Psychological Research Consortium (IT C19PRC): General Overview and Replication of the UK Study. Journal of Clinical Medicine, 10(1), 52. https://doi.org/10.3390/jcm10010052

Bu, F., Steptoe, A., \& Fancourt, D. (2020). Who is lonely in lockdown? Cross-cohort analyses of predictors of loneliness before and during the COVID-19 pandemic. Public Health, 186, 31-34. https://doi.org/10.1016/j.puhe.2020.06.036

Bu, F., Steptoe, A., Mak, H. W., \& Fancourt, D. (2021). Time use and mental health in UK adults during an 11-week COVID-19 lockdown: a panel analysis. The British Journal of Psychiatry. https://doi.org/10.1192/bjp.2021.44

Bulow, A., Keijsers, L., Boele, S., van Roekel, E., \& Denissen, J. (2020). Parenting adolescents in times of a pandemic: Changes in relationship quality, autonomy support, and parental control? psyarxiv. https://doi.org/10.31234/osf.io/g8kpf

Codella, R., Chirico, A., Lucidi, F., Ferrulli, A., La Torre, A., \& Luzi, L. (2020). The immunemodulatory effects of exercise should be favorably harnessed against COVID-19. Journal of Endocrinological Investigation. https://doi.org/10.1007/s40618-020-01403-5

Cohen, J. (1992). A power primer. Psychological Bulletin, 112(1), 155-159. https://doi.org/10.1037/0033-2909.112.1.155

Colvin, J., Chenoweth, L., Bold, M., \& Harding, C. (2004). Caregivers of older adults: Advantages and disadvantages of internet-based social support. Family Relations, 53(1), 49-57. https://doi.org/10.1111/j.1741-3729.2004.00008.x

Cooper, A. B., Pauletti, R. E., \& DiDonato, C. A. (2020). You, me, and no one else: Degree of social distancing and personality predict psychological wellness and relationship quality during the COVID-19 pandemic. psyarxiv. https://doi.org/10.31234/osf.io/w6dru

Daniels, K., Watson, D., \& Gedikli, C. (2017). Well-being and the social environment of work: A systematic review of intervention studies. International Journal of Environmental Research and Public Health, 14(8), 918. https://doi.org/10.3390/ijerph14080918

Ebrahimi, O. V., Hoffart, A., \& Johnson, S. U. (2020). The mental health impact of nonpharmacological interventions aimed at impeding viral transmission during the COVID19 pandemic in a general adult population and the factors associated with adherence to these mitigation strategies. https://doi.org/10.31234/osf.io/kjzsp

Peer] reviewing PDF | (2021:02:57922:2:0:NEW 21 Jun 2021) 
693 Fehr, B. (2004). Intimacy expectations in same-sex friendships: A prototype interaction model.

694

695

696

697

698

699

700

701

702

703

704

705

706

707

708

709

710

711

712

713

714

715

716

717

718

719

720

721

722

723

724

725

726

727

728

729

730

731

732

733

734

735

736

737

738

739

740

741

742
Journal of Personality and Social Psychology, 86(2), 265-284.

https://doi.org/10.1037/0022-3514.86.2.265

Feinstein, B. A., Hershenber, R., Bhatia, V., Latack, J. A., Meuwly, N., \& Davila, J. (2013). Negative social comparison on Facebook and depressive symptoms: Rumination as a mechanism. Psychology of Popular Media Culture, 2(3), 161-170. https://doi.org/10.1037/a0033111

Field, A. (2018). Discovering Statistics Using IBM Statistics (5th ed.). SAGE.

Fiorenzato, E., Zabberoni, S., Costa, A., \& Cona, G. (2020). Impact of COVID-19 lockdown and vulnerability factors on cogntive functioning and mental health in Italian population. medRxiv. https://doi.org/10.1101/2020.10.02.20205237

Fisher, J. R. W., Tran, T. D., Hammarberg, K., Sastry, J., Nguyen, H., Rowe, H., Popplestone, S., Stocker, R., Stubber, C., \& Kirkman, M. (2020). Mental health of people in Australia in the first month of COVID-19 restrictions: a national survey. Medical Journal of Australia. https://doi.org/10.5694/mja2.50831

Flaherty, L. M., Pearce, K. J., \& Rubin, R. B. (1998). Internet and face-to-face communication: Not functional alternatives. Communication Quarterly, 46(3), 250-268. https://doi.org/10.1080/01463379809370100

Galle, F., Sabella, E. A., Da Molin, G., De Giglio, O., Caggiano, G., Di Nonofrio, V., Ferracuti, S., Montagna, M. T., Liguori, G., Orsi, G. B., \& Napoli, C. (2020). Understanding knowledge and behaviors related to COVID-19 epidemic in Italian undergraduate students: The EPICO study. International Journal of Environmental Research and Public Health, 17, 3841. https://doi.org/10.3390/ijerph17103481

Gao, J., Zheng, P., Jia, Y., Chen, H., Mao, Y., Chen, S., Wang, Y., Fu, H., \& Dai, J. (2020). Mental health problems and social media exposure during COVID-19 outbreak. PLoS ONE, 15(4), e0231924. https://doi.org/10.1371/journal.pone.0231924

Girme, Y. U., Overall, N. C., \& Faingataa, S. (2014). "Date nights" take two: The maintenance function of shared relationship activities. Personal Relationships, 21, 125-149. https://doi.org/10.1111/pere.12020

Groarke, J. M., Berry, E., Graham-Wisener, L., McKenna-Plumley, P. E., McGlinchey, E., \& Armour, C. (2020). Loneliness in the UK during the COVID-19 pandemic: Crosssectional results from the COVID-19 psychological wellbeing study. PLoS ONE, 15(9), e0239698. https://doi.org/10.1371/journal.pone.0239698

Gruber, J., Prinstein, M. J., Clark, L. A., Rottenberg, J., Abromowitz, J. S., Albano, A. M., Aldao, A., Borelli, J. L., Chung, T., Davila, J., Forbes, E. E., Gee, D. G., Hall, G. C. N., Hallion, L. S., Hinshaw, S. P., Hofman, S. G., Hollon, S. D., Joormann, J., Kazdin, A. E., Klein, D. N., La Greca, A. M., Levenson, R. W., MacDonald, A. W., McKay, D., McLaughlin, K. A., Mendle, J., Miller, A. B., Neblett, E. W., Nock, M., Olatunji, B. O., Persons, J. B., Rozek, D. C., Schleider, J. L., Slavich, G. M., Teachman, B. A., Vine, V., \& Weinstock, L. M. (2020). Mental health and clinical psychological science in the time of COVID-19:

Peer] reviewing PDF | (2021:02:57922:2:0:NEW 21 Jun 2021) 
743

744

745

746

747

748

749

750

751

752

753

754

755

756

757

758

759

760

761

762

763

764

765

766

767

768

769

770

771

772

773

774

775

776

777

778

779

780

781

782

783

784

785

786

787

788

789

790

791

792

793

Challenges, opportunities, and a call to action. American Psychologist. https://doi.org/10.1037/amp0000707

Hamadani, J. D., Hasan, M. I., Baldi, A. J., Hossain, S. J., Shiraji, S., Bhuiyan, M. S. A., Mehrin, S. F., Fisher, J., Tofail, F., Tipu, S. M. M. U., Grantham-McGregor, S., Bigs, B., Braat, S., \& Pasricha, S. (2020). Immediate impact of stay-at-home orders to control COVID-19 transmission on socioeconomic conditions, food insecurity, mental health, and intimate partner violence in Bangladeshi women and their families: an interrupted time series. The Lancet Global Health, 8(11), e1380-e1389. https://doi.org/10.1016/S2214109X(20)30366-1

Holingue, C., Badillo-Goicoechea, E., Riehm, K. E., Veldhuis, C. B., Thrul, J., Johnson, R. M., Fallin, M. D., Kreuter, F., Stuart, E. A., \& Kalb, L. G. (2020). Mental distress during the COVID-19 pandemic among US adults without a pre-existing mental health condition: Findings from American trend panel survey. Preventive Medicine, 139, 106231. https://doi.org/10.1016/j.ypmed.2020.106231

Holman, E. A., Thompson, R. R., Garfin, D. R., \& Silver, R. C. (2020). The unfolding COVID-19 pandemic: A probability-based, nationally representative study of mental health in the U.S. Science advances, 6(42), eabd5390. https://doi.org/10.1126/sciadv.abd5390

Holmes, E. A., O'Connor, R. C., Perry, V. H., Tracey, I., Wessely, S., Arseneault, L., Ballard, C., Christensen, H., Silver, R. C., Everall, I., Ford, T., John, A., Kabir, T., King, K., Madan, I., Michie, S., Przybylski, A. K., Shafran, R., Sweeney, A., Worthman, C. M., Yardley, L., Cowan, K., Cope, C., Hotopft, M., \& Bullmoret, E. (2020). Multidisciplinary research priorities for the COVID-19 pandemic: a call for action for mental health science. The Lancet Psychiatry, 7, 547-560. https://doi.org/10.1016/S2215-0366(20)30168-1

Hsiang, S., Allen, D., Annan-Phan, S., Bell, K., Bolliger, I., Chong, T., Druckenmiller, H., Huang, L. Y., Hultgren, A., Krasovich, E., Lau, P., Lee, J., Rolf, E., Tseng, J., \& Wu, T. (2020). The effect of large-scale anti-contagion policies on the coronavirus (COVID-19) pandemic. medRxiv. https://doi.org/10.1101/2020.03.22.20040642

Huang, Y., \& Zhao, N. (2020). Generalized anxiety disorder, depressive symptoms and sleep quality during COVID-19 outbreak in China: a web-based cross-sectional survey. Psychiatry Research, 288, 112954. https://doi.org/10.1016/j.psychres.2020.112954

Jolly, E., Tamir, D. I., Burum, B., \& Mitchell, J. P. (2019). Wanting without enjoying: The social value of sharing experiences. PLoS ONE, 14(4), e0215318. https://doi.org/10.1371/journal.pone.0215318

Kalaitzaki, A. (2020). Positive and negative mental health outcomes and internal resources among the general population in Greece: A nation-wide survey amid COVID-19 lockdown. psyarxiv. https://doi.org/10.31234/osf.io/g29eb

Killgore, W. D. S., Cloonan, S. A., Taylor, E. C., \& Dailey, N. S. (2020). Loneliness: A signature mental health concern in the era of COVID-19. Psychiatry Research, 290, 113117. https://doi.org/10.1016/j.psychres.2020.113117

Kock, N. (2002). Evolution and media naturalness: A look at e-communication through a Darwinian theoretical lens. [http://aisel.aisnet.org/ics2002/34]. ICIS 2002 Proceedings, 
794

795

796

797

798

799

800

801

802

803

804

805

806

807

808

809

810

811

812

813

814

815

816

817

818

819

820

821

822

823

824

825

826

827

828

829

830

831

832

833

834

835

836

837

838

839

840

841

842

843

844
Kock, N. (2004). The psychobiological model: Towards a new theory of computer-mediated communication based on Darwinian evolution. Organization Science, 15(3), 327-348. https://doi.org/10.1287/orsc. 1040.0071

Lardone, A., Sorrentino, P., Giancamilli, F., Palombi, T., Simper, T., Mandolesi, L., Lucidi, F., Chirico, A., \& Galli, F. (2020). Psychosocial variables and quality of life during the COVID-19 lockdown: a correlational study on a convenience sample of young italians. PeerJ, 8, e10611. https://doi.org/10.7717/peerj.10611

Lee, S. A. (2020). How much "thinking" about COVID-19 is clinically dysfunctional? Brain, Behavior, and Immunity. https://doi.org/10.1016/j.bbi.2020.04.067

Li, S. H., Beames, J. R., Newby, J. M., Maston, K., Christensen, H., \& Werner-Seidler, A. (2020). The impact of COVID-19 on the lives and mental health of Australian adoloscents. medRxiv. https://doi.org/10.1101/2020.09.07.20190124

Lieberman, A., \& Schroeder, J. (2020). Two social lives: How differences between online and offline interaction influence social outcomes. Current Opinion in Psychology, 31, 16-21. https://doi.org/10.1016/j.copsyc.2019.06.022

Luchetti, M., Lee, J. H., Aschwanden, D., Seeker, A., Strickhouser, J. E., Terracciano, A., \& Sutin, A. (2020). The trajectory of loneliness in response to COVID-19. American Psychologist. https://doi.org/10.1037/amp0000690

Luo, M., \& Hancock, J. T. (2020). Self-disclosure and social media: motivations, mechanisms and psychological well-being. Current Opinion in Psychology, 31, 110-115. https://doi.org/10.1016/j.copsyc.2019.08.019

Marashi, M., Nicholson, E., Ogrodnik, M., Fenesi, B., \& Heisz, J. (2020). A mental health paradox: Mental health was both a motivator and barrier to physical activity during the COVID-19 pandemic. bioRxiv. https://doi.org/10.1101/2020.09.03.280719

Mazza, C., Ricci, E., Biondi, S., Colasanti, M., Ferracuti, S., Napoli, C., \& Roma, P. (2020). A nationawide survey of psychological distress among italian people during the COVID-19 pandemic: Immediate psychological responses and associated factors. International Journal of Environmental Research and Public Health, 17, 3165. https://doi.org/10.3390/ijerph17093165

Mesch, G., \& Talmund, I. (2006). The quality of online and offline relationships: The role of multiplexity and duration of social relationships. The Information Society, 22(3), 137-148. https://doi.org/10.1080/01972240600677805

Monin, J. K., Ali, T., Syed, S., Piechota, A., Lepore, M., Mourgues, C., Gaugler, J. E., Marottoli, R., \& David, D. (2020). Family communication in long-term care during a pandemic: Lessons for enhancing emotional experiences. The American Journal of Geriatric Psychiatry, 28(12), 1299-1307. https://doi.org/10.1016/j.jagp.2020.09.008

Newby, J. M., O'Moore, K., Tang, S., Christensen, H., \& Faasse, K. (2020). Acute mental health responses during the COVID-19 pandemic in Australia. PLOS ONE. https://doi.org/10.1371/journal.pone.0236562 
845

846

847

848

849

850

851

852

853

854

855

856

857

858

859

860

861

862

863

864

865

866

867

868

869

870

871

872

873

874

875

876

877

878

879

880

881

882

883

884

885

886

887

888

889

890

891

892

893

894

895
Ogolsky, B. G., \& Bowers, J. R. (2012). A meta-analytic review of relationship maintenance and its correlates. Journal of Social and Personal Relationships, 30(3), 343-367. https://doi.org/10.1177/0265407512463338

Ohannessian, C. M., Fagle, T., \& Salafia, C. (2020). Social media use and internalizing symptoms during early adolescence: The role of co-rumination. Journal of Affective Disorders, 280, 85-88. https://doi.org/10.1016/j.jad.2020.10.079

Ozamiz-Etxebarria, N., Mondragon, N. I., Santamaria, M. D., \& Gorrotxategi, M. P. (2020). Psychological symptoms during the two stages of lockdown in response to the COVID19 outbreak: An investigation in a sample of citizens in northern Spain. Frontiers in Psychology, 11, Article 1491. https://doi.org/10.3389/fpsyg.2020.01491

Pan, X., \& Hamilton, A. F. C. (2018). Why and how to use virtual reality to study human social interaction: The challenges of exploring a new research landscape. British Journal of Psychology, 109, 395-417. https://doi.org/10.1111/bjop.12290

Parris, L., Lannin, D. G., Hynes, K., \& Yazedjian, A. (2020). Exploring social media rumination: Associations with bullying, cyberbullying, and distress. Journal of Interpersonal Violence, 1-21. https://doi.org/10.1177/0886260520946826

Patrick, S. W., Henkhaus, L. E., Zickafoose, J. S., Lovell, K., Halvorson, A., Loch, S., Letterie, M., \& Davis, M. M. (2020). Well-being of parents and children during the COVID-19 pandemic: A national survey. Pediatrics, 146(4), e2020016824. https://doi.org/10.1542/peds.2020-016824

Phillipou, A., Meyer, D., Neill, E., Tan, E. J., Toh, W. L., Rheenen, T. E. V., \& Rossell, S. L. (2020). Eating and exercise behaviors in eating disorders and the general population during the COVID-19 pandemic in Australia: Initital results from the COLLATE project. International Journal of Eating Disorders, 1-8. https://doi.org/10.1002/eat.23317

Philpot, L. M., Ramar, P., Roellinger, D. L., Barry, B. A., Sharma, P., \& Ebbert, J. O. (2021). Changes in social realtionships during an initial "stay-at-home" phase of the COVID-19 pandemic: A longitudinal survey study in the U.S. Social Science \& Medicine, 274, 113779. https://doi.org/10.1016/j.socscimed.2021.113779

Pierce, M., Hope, H., Ford, T., Hatch, S., Hotopf, M., John, A., Kontopantelis, E., Webb, R., Wessely, S., McManus, S., \& Abel, K. M. (2020). Mental health before and during the COVID-19 pandemic: a longitudinal probability sample survey of the UK population. Lancet Psychiatry, 7, 883-892. https://doi.org/10.1016/S2215-0366(20)30308-4

Qiu, J., Shen, B., Zhao, M., Wang, Z., Xie, B., \& Xu, Y. (2020). A nationwide survey of psychological distress among Chinese people in the COVID-19 epidemic: implications and policy recommendations. General Psychiatry, 33, e100213. https://doi.org/10.1136/gpsych-2020-100213

Reis, H. T., Smith, S. M., Carmichael, C. L., Caprariello, P. A., Tsai, F., Rodrigues, A., \& Maniaci, M. R. (2010). Are you happy for me? How sharing positive events with others provides personal and interpersonal benefits. Journal of Personality and Social Psychology, 99(2), 311-329. https://doi.org/10.1037/a0018344

Peer] reviewing PDF | (2021:02:57922:2:0:NEW 21 Jun 2021) 
896

897

898

899

900

901

902

903

904

905

906

907

908

909

910

911

912

913

914

915

916

917

918

919

920

921

922

923

924

925

926

927

928

929

930

931

932

933

934

935

936

937

938

939

940

941

942

943

944

945

Roberts, T. J. (2018). Nursing home resident relationship types: What supports close relationships with peers \& staff? Journal of Clinical Nursing, 27(23-24), 4361-4372. https://doi.org/10.1111/jocn.14554

Rogers, S. L., Barblett, L., \& Robinson, K. (2016). Investigating the impact of NAPLAN on student, parent and teacher emotional distress in independent schools. The Australian Educational Researcher, 43(3), 327-343. https://doi.org/10.1007/s13384-016-0203-x

Rogers, S. L., Cruickshank, T., \& Nosaka, K. (2021). The Brief Emotional Experience Scale (BEES): Reliability and validity as a measure of positive and negative emotion. psyarxiv. https://doi.org/10.31234/osf.io/p4j7t

Rosedale, P. (2016). Virtual reality: The next disruptor: A new kind of worldwide communication. IEEE Consumer Electronics Magazine, 6(1), 48-50. https://doi.org/10.1109/MCE.2016.2614416

Rossell, S. L., Neill, E., Phillipou, A., Tan, E. J., Toh, W. L., Van Rheenen, T. E., \& Meyer, D. (2021). An overview of current mental health in the general population of Australia during the COVID-19 pandemic: Results from the COLLATE project. Psychiatry Research, 296, 1136600. https://doi.org/10.1016/j.psychres.2020.113660

Rossignac-Milon, M., \& Higgins, E. T. (2018). Epistemic companions: shared reality development in close relationships. Current Opinion in Psychology, 23, 66-71. https://doi.org/10.1016/j.copsyc.2018.01.001

Roy, D., S., T., Kar, S. K., Sharma, N., Verma, S. K., \& Kaushal, V. (2020). Study of knowledge, attitude, anxiety \& perceived mental healthcare need in Indian population during COVID19 pandemic. Asian Journal of Psychiatry, 51, 102083. https://doi.org/10.1016/j.ajp.2020.102083

Ryan, B. J., Coppola, D., Canyon, D. V., Brickhouse, M., \& Swienton, R. (2020). COVID-19 commuity stabilization and sustainability framework: An integration of the Maslow hierarchy of needs and social determinants of health. Disaster Medicine and Public Health Preparedness, 1-7. https://doi.org/10.1017/dmp.2020.109

Ryan, R. M., \& Deci, E. L. (2000). Self-determination theory and the facilitation of intrinsic motivation, social development, and well-being. American Psychologist, 55(1), 68-78. https://doi.org/10.1037110003-066X.55.1.68

Sameer, A. S., Khan, M. A., Nissar, S., \& Banday, M. Z. (2020). Assessment of mental health and various coping strategies among general population living under imposed COVIDlockdown across the world: A cross-sectional study. Ethics, Medicine and Public Health, 15, 100571. https://doi.org/10.1016/j.jemep.2020.100571

Saraswathi, I., Saikarthik, J., Kumar, K. S., Srinivasan, K. M., Ardanaari, M., \& Gunapriya, R. (2020). Impact of COVID-19 outbreak on the mental health status of undergraduate medical students in a COVID-19 treating medical college: a prospective longitudinal study. PeerJ, 8, e10164. https://doi.org/10.7717/peerj.10164

Peer] reviewing PDF | (2021:02:57922:2:0:NEW 21 Jun 2021) 
946

947

948

949

950

951

952

953

954

955

956

957

958

959

960

961

962

963

964

965

966

967

968

969

970

971

972

973

974

975

976

977

978

979

980

981

982

983

984

985

986

987

988

989

990

991

992

993

994

995

996

Seymour, M., Reimer, K., \& Kay, J. (2018). Actors, avatars and agents: Potentials and implications of natural face technology for the creation of realistic visual presence. Journal of the Association for Information Systems, 19(10), 953-981. https://doi.org/10.17705/1jais.00515

Seymour, M., Yuan, L., Dennis, A. R., \& Riemer, K. (2019). Crossing the uncanny valley? Understanding affinity, trustworthiness, and preference for more realistic virtual humans in immersive environments 52nd Hawaii International Conference on System Sciences, http://hdl.handle.net/10125/59615

Shaw, Y., Pollio, D. E., \& North, C. S. (2020). Changes in perceptions and attitudes towards self and others in survivors of the September 11, 2001, terrorist attacks. Traumatology. https://doi.org/10.1037/trm0000260

Skead, N. K., \& Rogers, S. L. (2016). Running to well-being: A comparative study on the impact of exercise on the physical and mental health of law and psychology students. International Journal of Law and Psychiatry, 49, 66-74. https://doi.org/10.1016/j.ijlp.2016.05.012

Skead, N. K., Rogers, S. L., \& Doraisamy, J. (2018). Looking beyond the mirror: Psychological distress; disordered eating, weight and shape concerns; and maladaptive eating habits in lawyers and law students. International Journal of Law and Psychiatry, 61, 90-102. https://doi.org/10.1016/j.ijlp.2018.06.002

Sprecher, S., \& Treger, S. (2015). The benefits of turn-taking reciprocal self-disclosure in getacquainted interactions. Personal Relationships, 22, 460-475. https://doi.org/10.1111/pere.12090

Stanton, R., To, Q. G., Khalesi, S., Williams, S. L., Alley, S. J., Thwaite, T. L., Fenning, A. S., \& Vandelanotte, C. (2020). Depression, anxiety and stress during COVID-19: Associations with changes in physical activity, sleep, tobacco and alcohol use in Australian adults. International Journal of Environmental Research and Public Health, 17(11), 4065. https://doi.org/10.3390/ijerph17114065

Stults-Kolehmainen, M. A., \& Sinha, R. (2014). The effects of stress on physical activity and exercise. Sports Medicine, 44, 81-121. https://doi.org/10.1007/s40279-013-0090-5

Timming, A. R., French, M. T., \& Mortensen, K. (2021). Health anxiety versus economic anxiety surrounding COVID-19: An analysis of psycholoical distress in the early stages of the pandemic. Journal of Affective Disorders Reports, 5, 100152. https://doi.org/10.1016/j.jadr.2021.100152

Titov, N., Staples, L., Kayrouz, R., Cross, S., Karin, E., Ryan, K., Dear, B., \& Nielssen, O. (2020). Rapid report: Early demand, profiles and concerns of mental health users during the coronavirus (COVID-19) pandemic. Internet Interventions, 21, 100327. https://doi.org/10.1016/j.invent.2020.100327

Twenge, J. M., \& Joiner, T. E. (2020). Mental distress among U.S. adults during the COVID-19 pandemic. Journal of Clinical Psychology, 76(12), 2170-2182. https://doi.org/10.1002/jclp.23064

Peer) reviewing PDF | (2021:02:57922:2:0:NEW 21 Jun 2021) 
997

998

999

1000

1001

1002

1003

1004

1005

1006

1007

1008

1009

1010

1011

1012

1013

1014

1015

1016

1017

1018

1019

1020

1021

1022

1023

1024

1025

1026

1027

1028

1029

1030

1031

1032

1033

1034

1035

1036

1037

1038

1039

1040

1041

1042

1043 van Agteren, J., Bartholomaeus, J., Fassnacht, D. B., Iasiello, M., Ali, K., Lo, L., \& Kyrios, M. (2020). Using internet-based psychological measurement to capture the deteriorating community mental health profile during COVID-19: Observational study. JMIR Mental Health, 7(6), e20696. https://doi.org/10.2196/20696

van Tilburg, T. G., Steinmetz, S., Stolte, E., van der Roest, H., \& de Vries, D. H. (2020). Loneliness and mental health during the COVID-19 pandemic: A study among dutch older adults. Journals of Gerontology: Social Sciences. https://doi.org/10.1093/geronb/gbaa111

Walther, J. B. (1996). Computer-mediated communication: Impersonal, interpersonal, and hyperpersonal interaction. Communication Research, 23(1), 3-43. https://doi.org/10.1177/009365096023001001

Walther, J. B., \& Parks, M. R. (2002). Cues filtered out, cues filtered in. In Handbook of Interpersonal Communication (Vol. 3, pp. 529-563). https://www.researchgate.net/profile/Joseph Walther/publication/239489124 Cues Filte red Out Cues Filtered In ComputerMediated Communication and Relationships/links/0a85e538f3d5705044000000.pdf

Wang, C., Pan, R., Wan, X., Tan, Y., Xu, L., Ho, C. S., \& Ho, R. C. (2020). Immediate psychological responses and associated factors during the initial stage of the 2019 coronavirus disease (COVID-19) epidemic among the general population in China. International Journal of Environmental Research and Public Health, 17, 1729. https://doi.org/10.3390/ijerph17051729

Westrupp, E. M., Stokes, M. A., Fuller-Tyszkiewicz, M., Berkowitz, T. S., Capic, T., Khor, S., Greenwood, C. J., Mikocka-Walus, A., Sciberras, E., Youssef, G. J., Olsson, C. A., \& Hutchinson, D. (2021). Subjective wellbeing in parents during the COVID-19 pandemic in Australia. Journal of Psychosomatic Research, 145, 110482. https://doi.org/10.1016/j.jpsychores.2021.110482

Wilson, G., Gates, J. R., Vijaykumar, S., \& Morgan, D. (2020). Understanding the experiences of older adults using technology to stay connected: $A$ facilitator or creator of new vulnerabilities. N. University. https://researchportal.northumbria.ac.uk/files/33081065/Final_project_report_Wilson_Ga tes Vijaykumar Morgan 2020002 .pdf

Yucel, M., Sjobeck, G., Glass, R., \& Rottman, J. (2020). Being in the know: Social network analysis of gossip and friendship on college campuses. psyarxiv. https://doi.org/10.31234/osf.io/q8m7u

Zacher, H., \& Rudolph, C. W. (2020). Individual differences and changes in subjective wellbeing during the early stages of the COVID-19 pandemic. American Psychologist. https://doi.org/10.1037/amp0000702 
Figure 1

Emotional well-being, physical well-being, and frequency of exercise during lockdown compared with estimates for same time last year.

Violin plots of participant estimates for last year compared to the prior month during COVID-19 lock-down for (a) Emotional well-being as measured by the Brief Emotional Experience Scale (BEES) (b) Physical well-being as measured by the Brief Emotional Experience Physical Scale (c) Exercise as measured by three items asking frequency of low, moderate and high intensity exercise combined into an overall composite frequency of exercise score.
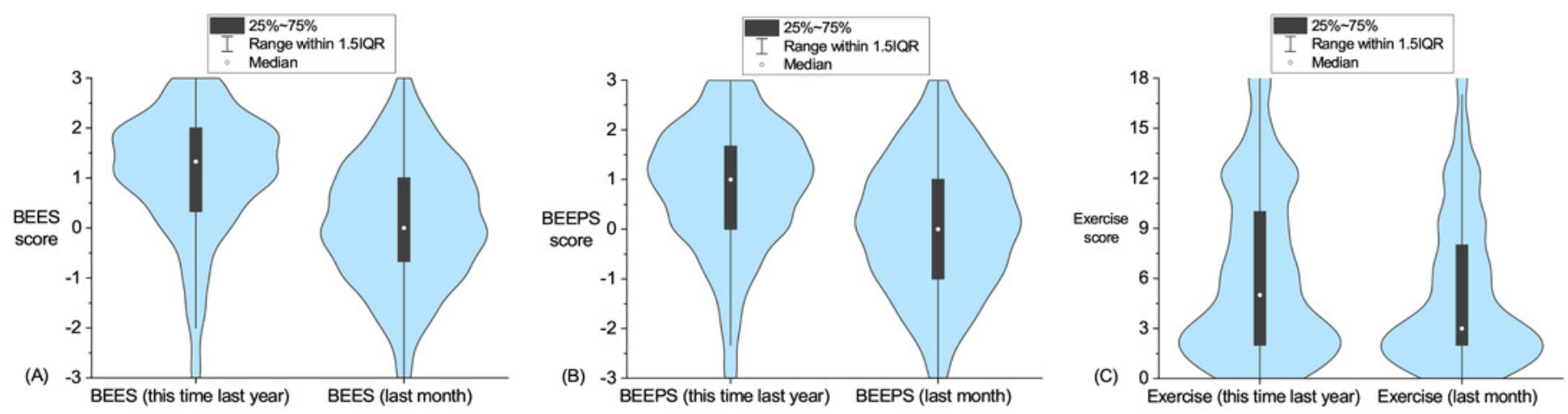
Figure 2

Participants ratings of the direct impact they felt COVID-19 lockdown was having upon multiple aspects of their lives.

Over the past month, the impact on my life due to the COVID-19 outbreak:

Deteriorated a lot Deteriorated somewhat No change Improved somewhat Improved a lot

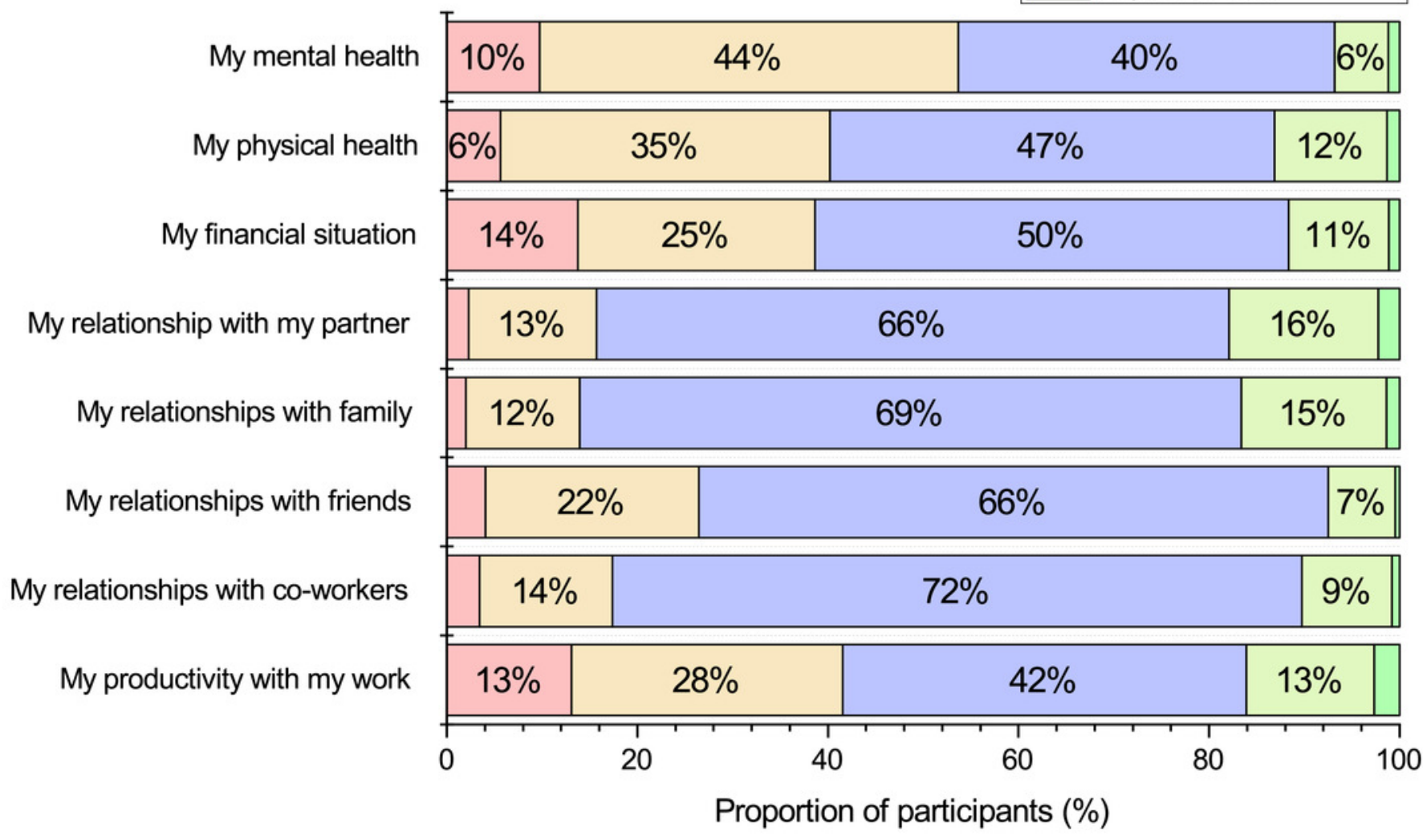


Figure 3

Participant self-reported extent of COVID-19 related concern across multiple factors.

How concerned are you about each of the following:

Not concerned Slightly concerned Very concerned Extremely concerned

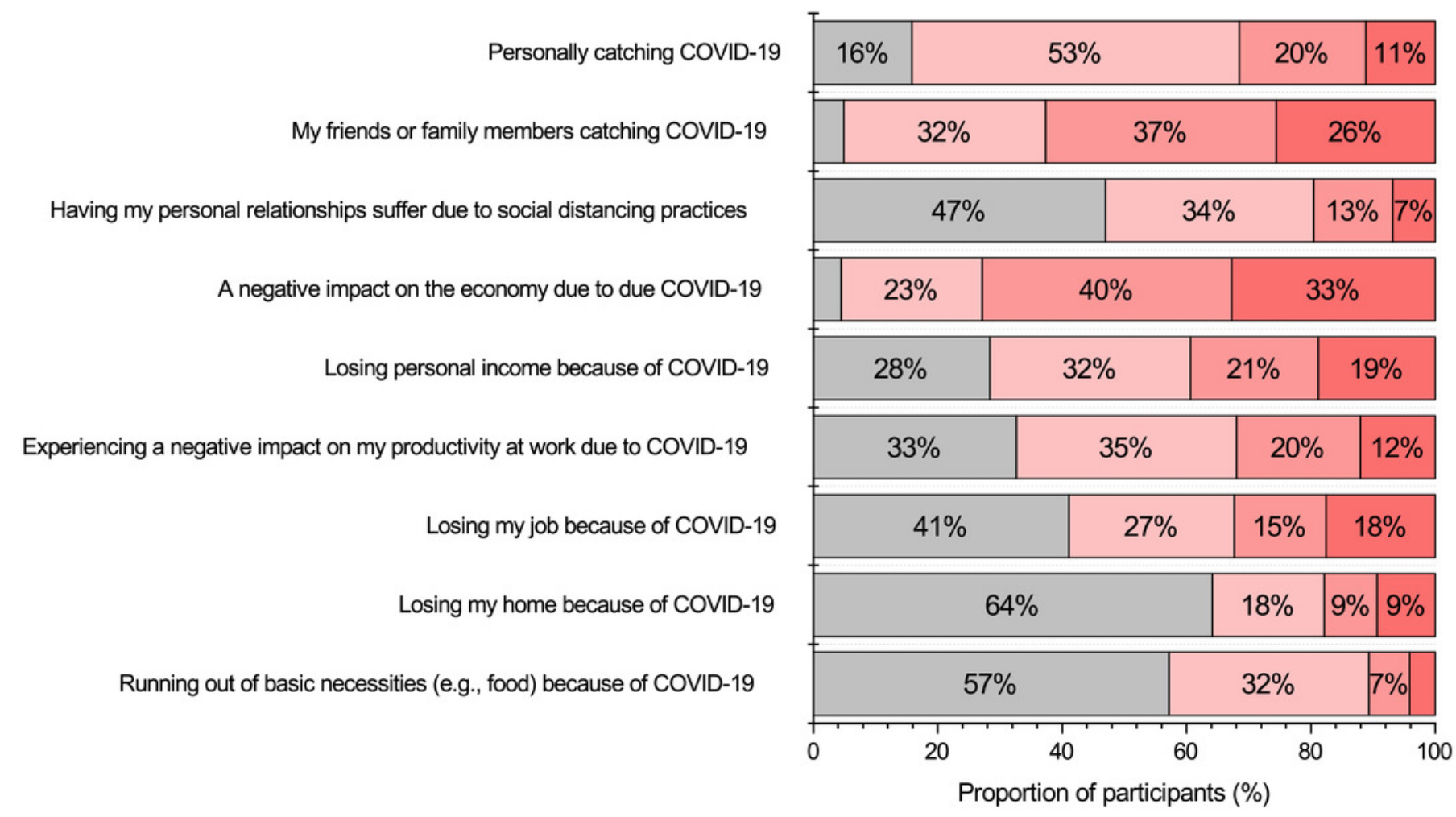


Figure 4

Participant self-reported frequency of engagement with COVID-19 information, talking with people about COVID-19, and thinking about COVID-19.

Over the past month, I have been:
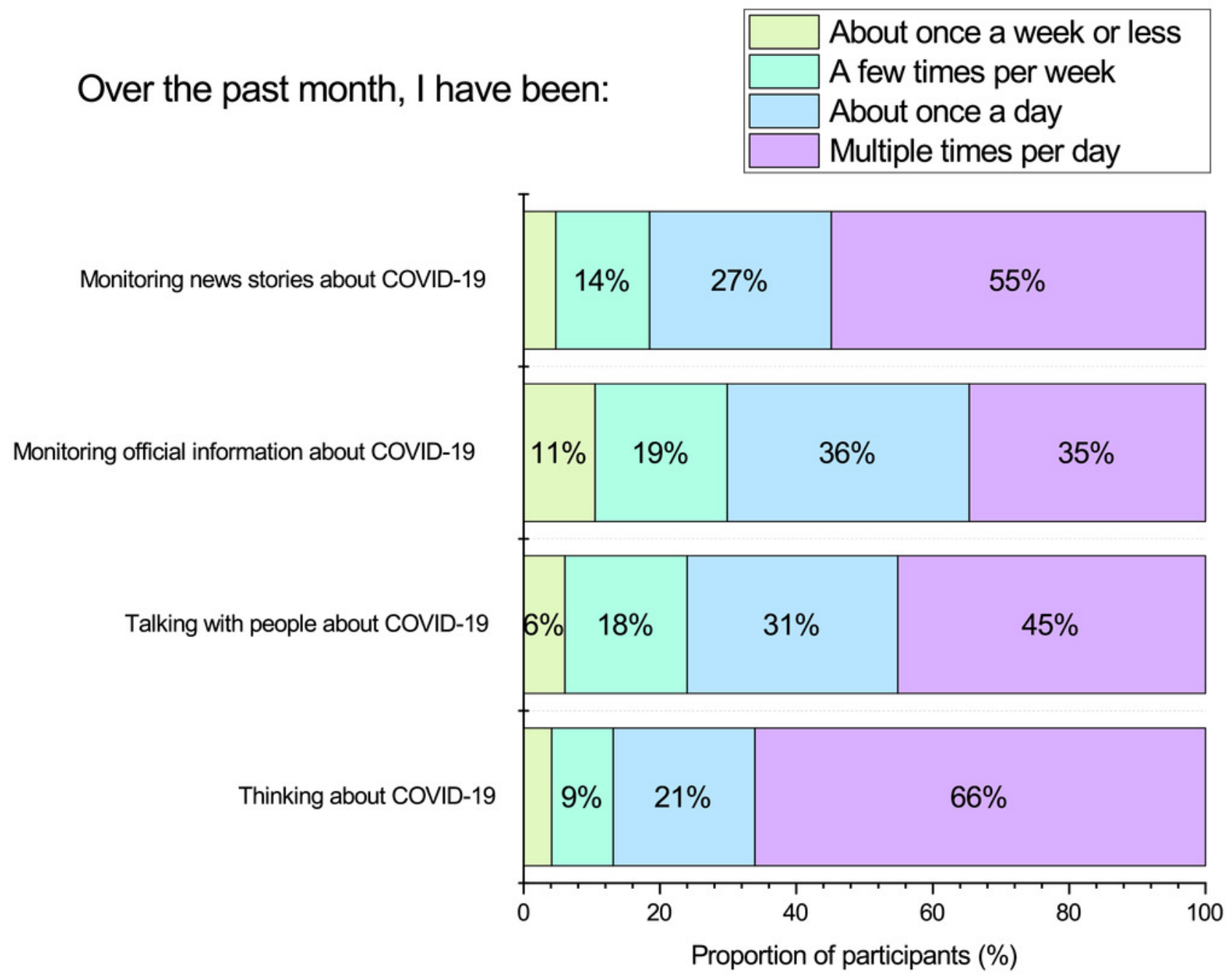
Figure 5

Participant self-reported changes in social behaviour during the COVID-19 lock-down period.

Over the past month, the changes in my behaviour due to the COVID-19 outbreak:

\begin{tabular}{|l|l|}
\hline & A lot less \\
\hline \hline & Somewhat less \\
\hline$\square$ & No change \\
\hline$\square$ & Somewhat more \\
\hline \hline & A lot more \\
\hline
\end{tabular}

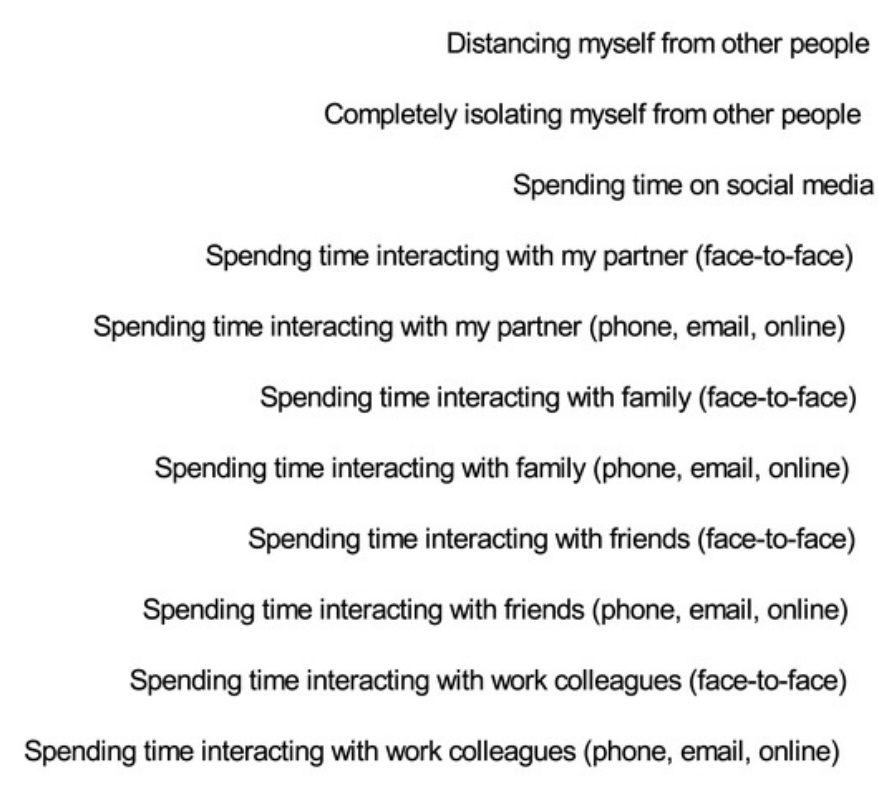

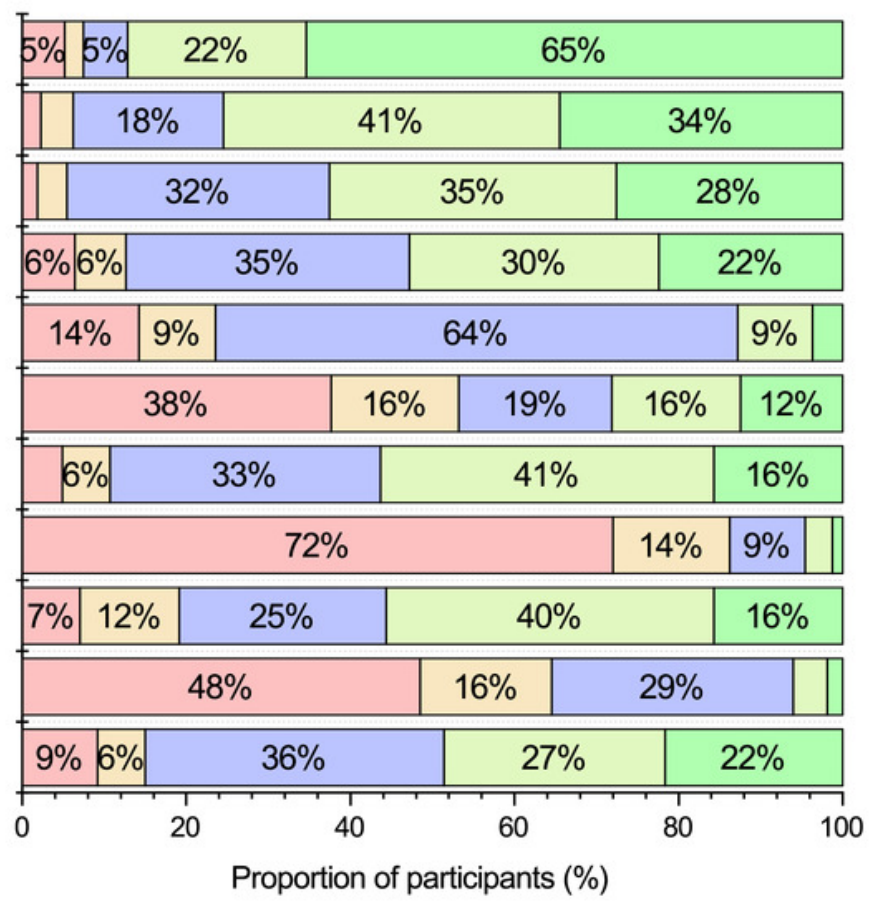




\section{Figure 6}

Associations between change in communication and change in perceived relationsip quality.

Charts are presented that graphically show the associations between change in communication and change in perceived relationship quality. The left column (A-D) shows change in face-to-face communication split by change in relationship quality. The right column (E-H) shows change in technology-mediated communication split by change in relationship quality. Each row presents a different relationship type 1 - Partner, 2 - Family, 3 Friends, and 4 - Co-workers. 


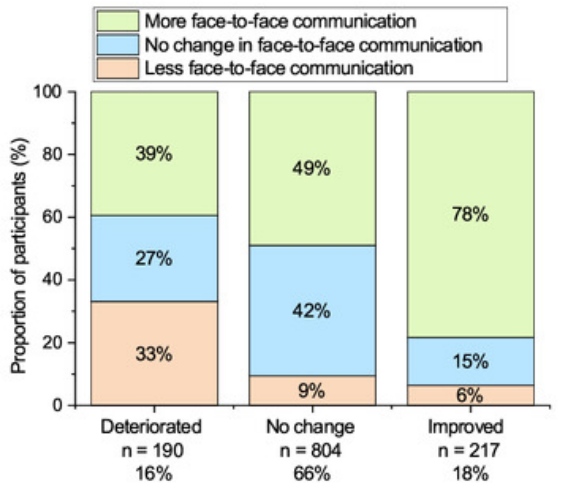

(A) Perceived change in relationship quality with partner $(n=1211)$

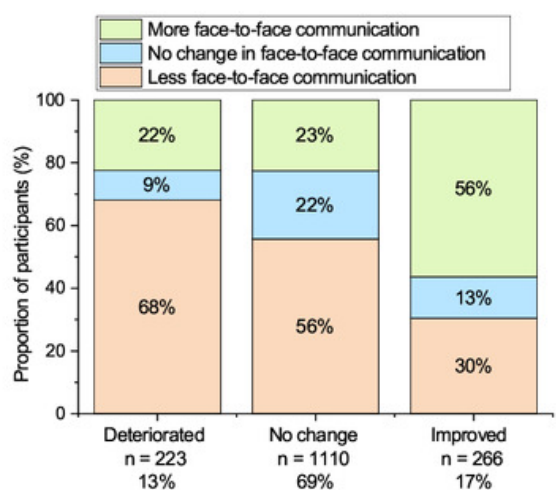

(B) Perceived change in relationship quality with family $(n=1599)$

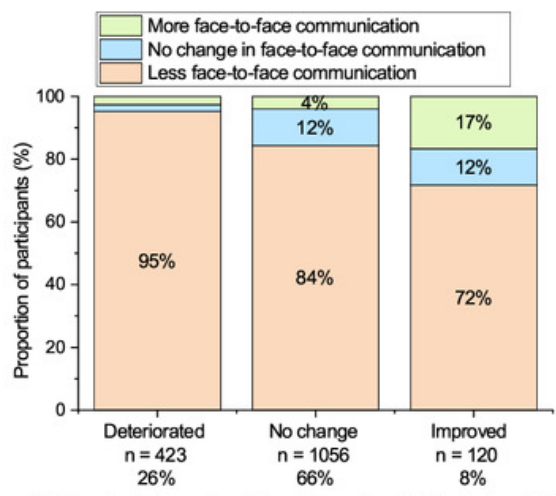

(C) Perceived change in relationship quality with friends $(n=1599)$

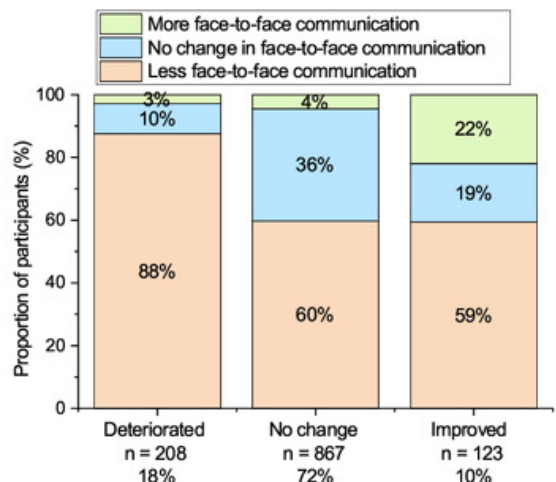

(D) Perceived change in relationship quality with co-workers $(n=1198)$

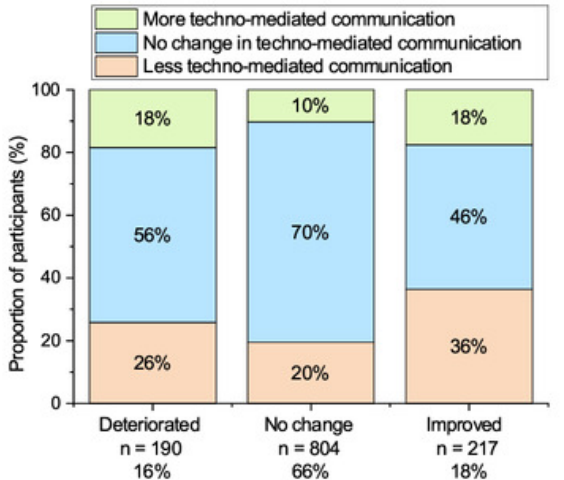

(E) Perceived change in relationship quality with partner $(n=1211)$

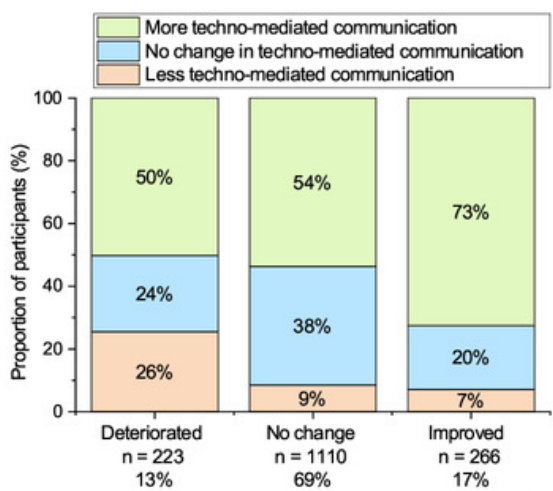

(F) Perceived change in relationship quality with family $(n=1599)$

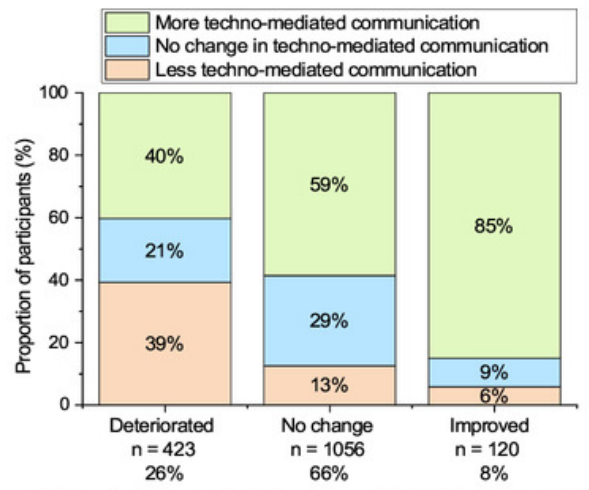

(G) Perceived change in relationship quality with friends $(n=1599)$

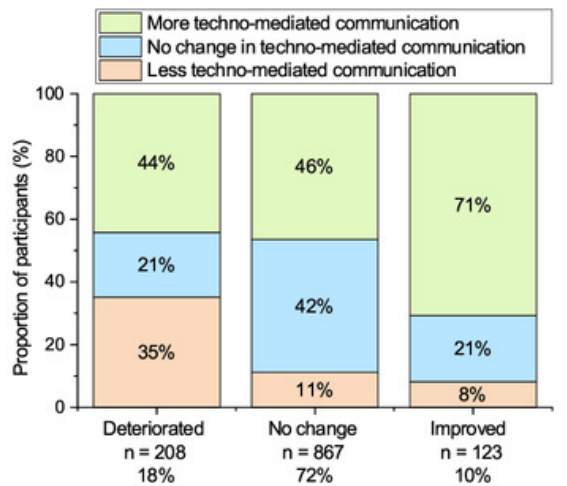

(H) Perceived change in relationship quality with co-workers $(n=1198)$ 


\section{Figure 7}

COVID-19 cases in the months of March and April for each Australian state and territory in 2020 .

COVID-19 cases in the months of March and April for each Australian state and territory in 2020. NSW $=$ New South Wales; VIC = Victoria; $Q L D=$ Queensland; $W A=$ Western Australia; $\mathrm{SA}=$ South Australia; $\mathrm{TAS}=$ Tasmania; $\mathrm{ACT}=$ Australian Capital Territory; $\mathrm{NT}=$ Northern Territory. This chart was created using statistics available via the Australian government Department of Health National Notifiable Diseases Surveillance System accessible at http://www9.health.gov.au/cda/source/cda-index.cfm 


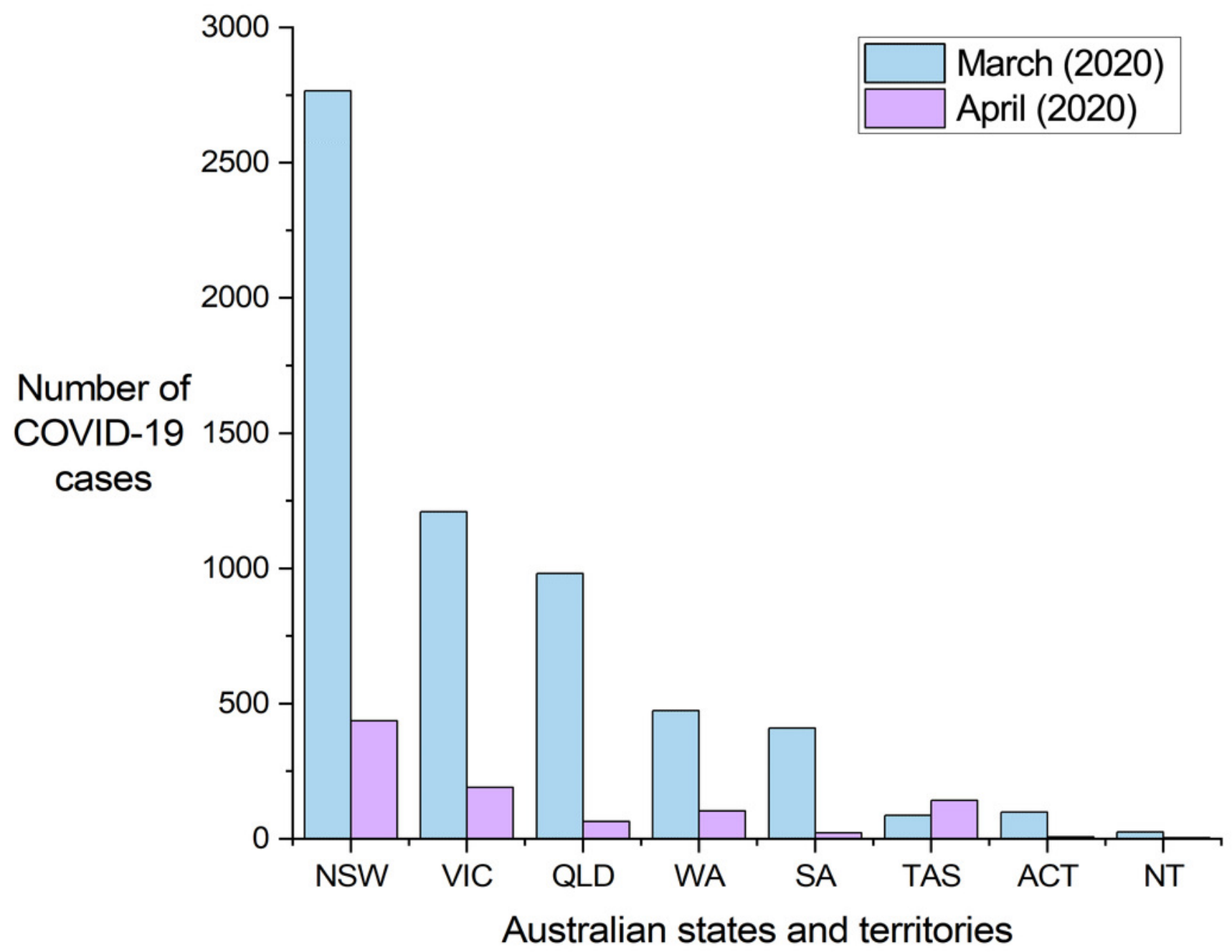




\section{Table $\mathbf{1}$ (on next page)}

Pearson correlations between self-report ratings for the BEES, BEEPS, and exercise during lockdown, and reflections on the prior year. 


\begin{tabular}{lcccccc}
\hline & 1. & 2. & 3. & 4. & 5. & 6. \\
\hline 1. BEES (lockdown) & 1 & & & & & \\
2. BEEPS (lockdown) & $.60^{*}$ & 1 & & & & \\
3. Exercise (lockdown) & $.17^{*}$ & $.40^{*}$ & 1 & & & \\
4. BEES (last year) & $.18^{*}$ & $.20^{*}$ & .01 & 1 & & \\
5. BEEPS (last year) & $.10^{*}$ & $.34^{*}$ & $.18^{*}$ & $.57^{*}$ & 1 & \\
6. Exercise (last year) & .01 & $.12^{*}$ & $.56^{*}$ & $.12^{*}$ & $.48^{*}$ & 1 \\
\hline
\end{tabular}

$1 \quad{ }^{*} p<.001$

2 


\section{Table 2 (on next page)}

Spearman correlations between mental/physical health, change in finances, change in work productivity, and change in relationship quality across partner, family, friends, and work colleagues. 


\begin{tabular}{|c|c|c|c|c|c|c|c|c|c|c|}
\hline & 1 & 2 & 3 & 4 & 5 & 6 & 7 & 8 & 9 & 10 \\
\hline 1. BEES (lockdown) & 1 & & & & & & & & & \\
\hline 2. BEEPS (lockdown) & $.58^{*}$ & 1 & & & & & & & & \\
\hline 3.Mental health change & $.64^{*}$ & $.46^{*}$ & 1 & & & & & & & \\
\hline 4.Physical health change & $.35^{*}$ & $.49 *$ & $.39 *$ & 1 & & & & & & \\
\hline 5.Finances change & $.26^{*}$ & $.14^{*}$ & $.22 *$ & $.17^{*}$ & 1 & & & & & \\
\hline 6.Relationship - partner & $.24^{*}$ & $.18^{*}$ & $.27 *$ & $.20^{*}$ & $.11^{*}$ & 1 & & & & \\
\hline 7.Relationships - Family & $.15^{*}$ & $.11^{*}$ & $.20 *$ & $.15^{*}$ & $.12^{*}$ & $.37^{*}$ & 1 & & & \\
\hline 8.Relationships - Friends & $.20^{*}$ & $.19 *$ & $.23 *$ & $.18^{*}$ & $.10^{*}$ & $.20 *$ & $.34 *$ & 1 & & \\
\hline 9.Relationships - Work colleagues & $.17^{*}$ & .08 & $.15^{*}$ & $.14^{*}$ & $.13^{*}$ & $.15^{*}$ & $.15^{*}$ & $.31^{*}$ & 1 & \\
\hline 10.Work productivity change & $.22^{*}$ & $.21^{*}$ & $.28 *$ & $.19 *$ & $.24^{*}$ & $.14^{*}$ & .10 & $.13^{*}$ & $.30 *$ & 1 \\
\hline
\end{tabular}

$1 \quad{ }^{*} p<.001$

2 
Table 3(on next page)

Spearman correlations between mental health, and a range of concerns regarding COVID-19. 


\begin{tabular}{|c|c|c|c|c|c|c|c|c|c|c|c|}
\hline & 1 & 2 & 3 & 4 & 5 & 6 & 7 & 8 & 9 & 10 & 11 \\
\hline 1.BEES (lockdown) & 1 & & & & & & & & & & \\
\hline 2.Mental health change & $.64^{*}$ & 1 & & & & & & & & & \\
\hline 3.Catching COVID (self) & $-.27^{*}$ & $-.11 *$ & 1 & & & & & & & & \\
\hline 4.Catching COVID (F/F) & $-.32 *$ & $-.17^{*}$ & $.60^{*}$ & 1 & & & & & & & \\
\hline 5.Relationships suffer & $-.43^{*}$ & $-.42^{*}$ & $.10^{*}$ & $.17^{*}$ & 1 & & & & & & \\
\hline 6.Economy & $-.18^{*}$ & $-.15^{*}$ & $.10^{*}$ & $.13^{*}$ & $.23^{*}$ & 1 & & & & & \\
\hline 7.Personal income & $-.30 *$ & $-.22 *$ & $.14^{*}$ & $.24^{*}$ & $.24^{*}$ & $.26^{*}$ & 1 & & & & \\
\hline 8. Work productivity & $-.32 *$ & $-.25^{*}$ & $.19 *$ & $.20^{*}$ & $.29 *$ & $.21 *$ & $.53^{*}$ & 1 & & & \\
\hline 9.Losing job & $-.30 *$ & $-.22 *$ & $.15^{*}$ & $.19 *$ & $.26^{*}$ & $.22 *$ & $.68 *$ & $.52 *$ & 1 & & \\
\hline 10.Losing home & $-.27^{*}$ & $-.17^{*}$ & $.16^{*}$ & $.19 *$ & $.31^{*}$ & $.20 *$ & $.53^{*}$ & $.36^{*}$ & $.55^{*}$ & 1 & \\
\hline $\begin{array}{l}\text { 11.Running out of } \\
\text { necessities }\end{array}$ & $-.29 *$ & $-.21 *$ & $.28^{*}$ & $.26^{*}$ & $.35^{*}$ & $.10^{*}$ & $.24 *$ & $.27^{*}$ & $.28^{*}$ & $.44^{*}$ & 1 \\
\hline
\end{tabular}

$1 \quad * p<.001$

2

3 
Table 4 (on next page)

Spearman correlations between mental health, and amount of attention given to COVID-19. 


\begin{tabular}{lcccccc}
\hline & 1. & 2. & 3. & 4. & 5. & 6. \\
\hline 1.BEES (lockdown) & 1 & & & & & \\
2.Mental health change & $.64^{*}$ & 1 & & & & \\
3.Monitoring news & $-.12^{*}$ & -.06 & 1 & & & \\
4.Monitoring official sources & $-.11^{*}$ & -.03 & $.64^{*}$ & 1 & & \\
5.Talking about COVID & $-.10^{*}$ & -.07 & $.42^{*}$ & $.40^{*}$ & 1 & \\
6.Thinking about COVID & $-.27^{*}$ & $-.18^{*}$ & $.46^{*}$ & $.40^{*}$ & $.55^{*}$ & 1 \\
\hline
\end{tabular}

$1 \quad * p<.001$

2

3 


\section{Table 5 (on next page)}

Spearman correlations between change in perceived relationship quality with change in face-to-face and technology-mediated interaction. 


\begin{tabular}{lcccc}
\hline & $\begin{array}{c}\text { Partner } \\
\text { relationship } \\
\text { change }\end{array}$ & $\begin{array}{c}\text { Family } \\
\text { relationship } \\
\text { change }\end{array}$ & $\begin{array}{c}\text { Friends } \\
\text { relationship } \\
\text { change }\end{array}$ & $\begin{array}{c}\text { Work colleagues } \\
\text { relationship } \\
\text { change }\end{array}$ \\
\hline Face-to-face interaction change & $.27^{*}$ & $.27^{*}$ & $.20^{*}$ & $.21^{*}$ \\
Tech-mediated interaction change & -.06 & $.15^{*}$ & $.29^{*}$ & $.19^{*}$ \\
\hline
\end{tabular}

$1 \quad * p<.001$

2 